\title{
Evaluation of Wildland Fire Fighter Exposures during Fuel Reduction Projects
}

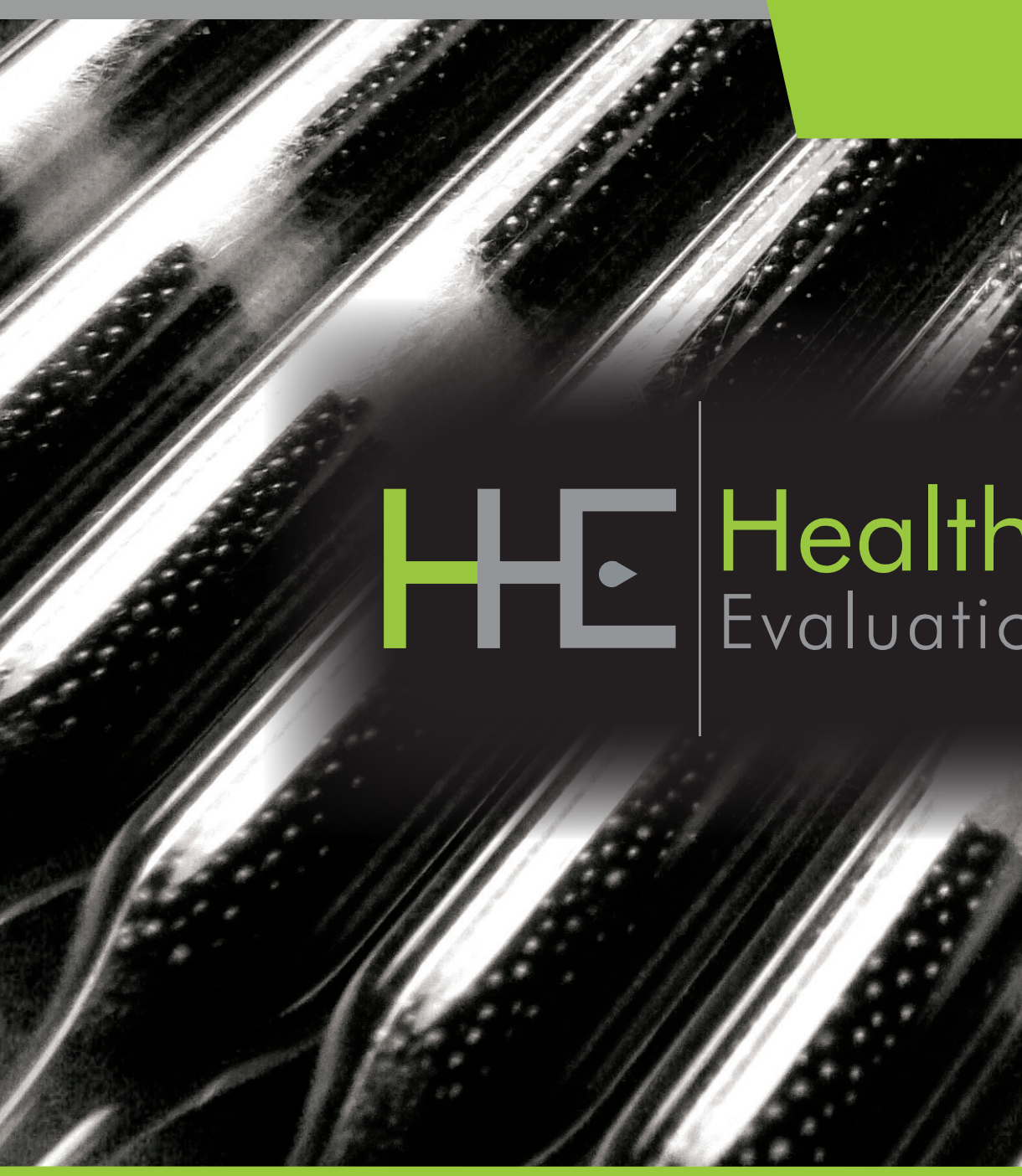

HHE Report No. 2015-0028-3330 March 2019
Jessica G. Ramsey, MS, CPE Judith Eisenberg, MD, MS

Douglas Wiegand, $\mathrm{PhD}$ Scott E. Brueck, MS, CIH Thomas W. McDowell, PhD 


\section{Contents}

Highlights.

Abbreviations ...................................... iii

Introduction ............................................ 1

Methods ............................................. 2

Results ................................................. 7

Discussion .......................................... 18

Conclusions........................................ 22

Recommendations.......................... 23

Appendix A $\ldots \ldots \ldots \ldots \ldots \ldots \ldots \ldots \ldots \ldots \ldots \ldots \ldots . . . \ldots \ldots$

Appendix B ........................................ 32

References............................................ 42

Acknowledgements............................ 47

The employer is required to post a copy of this report for 30 days at or near the workplace(s) of affected employees. The employer must take steps to ensure that the posted report is not altered, defaced, or covered by other material.

The cover photo is a close-up image of sorbent tubes, which are used by the HHE Program to measure airborne exposures. This photo is an artistic representation that may not be related to this Health Hazard Evaluation. Photo by NIOSH. 


\section{Highlights of this Evaluation}

The Health Hazard Evaluation Program received a request from a state-based wildland fire management program. Employer representatives were concerned about potential exposures to hand-transmitted vibration, wood chipper dust, noise, and carbon monoxide related to chain saw and wood chipper use among wildland fire fighters. The requestors were also concerned about safety climate and job stress issues among wildland fire fighters. We conducted three site visits; pre- and post-fire season visits in 2015 in which informal interviews were conducted focusing on general medical issues, psychosocial factors, and job stress. A third visit occurred in April 2016 for sampling and questionnaire administration.

\section{What We Did}

- We measured fire fighters' exposures to carbon monoxide and wood dust in the air for two shifts during a fuel reduction project.

- We measured fire fighters' noise exposures during training exercises and a fuel reduction project.

- We measured fire fighters' exposures to hand-transmitted vibration during chain saw use.

- We asked fire fighters to complete a questionnaire covering work history and symptoms associated with wood dust, hand-arm vibration, carbon monoxide, and noise exposures.

- We reviewed the hearing test results for 69 fire fighters.

- We held confidential medical interviews with 56 fire fighters about health symptoms, safety climate, job stress, psychosocial factors at work, and sleep.

\section{What We Found}

We evaluated wildland fire fighters exposures to noise, vibration, carbon monoxide, and wood dust during fuel reduction activities. We found evidence of high noise exposures and hearing loss, overexposures to vibration and symptoms that could be consistent with hand-arm vibration syndrome, overexposures to wood dust and possible wood dust allergy symptoms. We also found occasional excursions over occupational exposure limits. Fire fighters reported a strong safety climate and moderate job stress.

- None of the fire fighters' full-shift exposures to carbon monoxide were above occupational exposure limits. However, their exposures were occasionally above the National Institute for Occupational Safety and Health ceiling limit of 200 parts per million of air.

- Fire fighters' exposures to wood dust in the air were sometimes higher than occupational exposure limits. Some fire fighters reported asthma-like symptoms and rashes, which could be related to exposure to wood dust.

- Fire fighters' noise exposures when using or working near the chain saws or wood chippers were above noise exposure limits. Hearing test results showed that some fire fighters had hearing threshold shifts. Some fire fighters were unsure/unaware of their hearing tests results. 
- During fuel reduction activities, fire fighters were exposed to hand-transmitted vibration levels from chain saws above the daily exposure limit value. Over $70 \%$ of fire fighters reported one or more symptoms that could be consistent with hand-arm vibration syndrome.

- Wildland fire fighters reported a strong safety climate, moderate job stress, favorable perceptions of various psychosocial factors at work, and decreased sleep quality at the end of the fire season.

\section{What the Employer Can Do}

- Reduce chain saw use to three hours or less during a work shift to reduce daily handtransmitted vibration exposures.

- Maintain chain saws to reduce carbon monoxide exhaust, wood dust, and handtransmitted vibration exposures.

- Talk to fire fighters about job demands and how they affect job stress, burnout, and job satisfaction.

- Ensure fire fighters receive adequate training on the importance of good sleep habits, the hazards associated with fatigue at work, and strategies for managing them.

- Encourage fire fighters who develop health symptoms related to work to get evaluated by their healthcare provider.

- Require fire fighters to wear both insert ear plugs and ear muffs when operating and feeding the chipper. Improve communication of hearing test results to fire fighters.

- Require fire fighters to wear N95 filtering facepiece respirators when using chain saws during fuel reduction activities until wood dust exposures are reduced. Educate wildland fire fighters regarding health effects that may develop if sensitization to wood dust occurs.

- Include fire fighters required to wear respirators in a respiratory protection program.

\section{What Fire Fighters Can Do}

- Turn off powered equipment and seek medical attention if you experience headaches, dizziness, drowsiness, nausea, or tightness across the chest.

- Report work-related health symptoms, strains, and pain to your supervisor. Promptly seek medical attention from a healthcare provider for these symptoms. Be sure to tell them you are a wildland fire fighter. This will help your healthcare provider check for other possible work-related health issues.

- Use only hearing protection provided by the agency. Keep hearing protection clean or replace disposable earplugs when dirty.

- Do not have facial hair (beards) that interferes with the sealing surface of respirators. 


\section{Abbreviations}

\begin{tabular}{|c|c|}
\hline ACGIH® & American Conference of Governmental Industrial Hygienists \\
\hline $\mathrm{AL}$ & Action level \\
\hline ANSI & American National Standards Institute \\
\hline ASHA & American Speech-Language-Hearing Association \\
\hline AV & Anti-vibration \\
\hline CFR & Code of Federal Regulations \\
\hline $\mathrm{CO}$ & Carbon monoxide \\
\hline $\mathrm{COHb}$ & Carboxyhemoglobin \\
\hline $\mathrm{dB}$ & Decibel \\
\hline dBA & Decibels, A-scale \\
\hline DEAV & Daily exposure action value \\
\hline DELV & Daily exposure limit value \\
\hline HAVS & Hand-arm vibration syndrome \\
\hline HPD & Hearing protection device \\
\hline $\mathrm{Hz}$ & Hertz \\
\hline IDLH & Immediately dangerous to life and health \\
\hline ISO & International Organization for Standardization \\
\hline $\mathrm{m} / \mathrm{s}^{2}$ & Meters per second squared \\
\hline $\mathrm{mg} / \mathrm{m}^{3}$ & Milligrams per cubic meter \\
\hline NIHL & Noise-induced hearing loss \\
\hline NIOSH & National Institute for Occupational Safety and Health \\
\hline OEL & Occupational exposure limit \\
\hline OSHA & Occupational Safety and Health Administration \\
\hline PEL & Permissible exposure limit \\
\hline ppm & Parts per million \\
\hline REL & Recommended exposure limit \\
\hline rms & Root-mean-square \\
\hline STS & Standard threshold shift \\
\hline TLV® & Threshold limit value \\
\hline TWA & Time-weighted average \\
\hline VWF & Vibration white finger \\
\hline
\end{tabular}


This page left intentionally blank 


\section{Introduction}

Employer representatives of a state-based wildland fire management program were concerned about the potential exposures to vibration, wood dust, carbon monoxide (CO), and noise along with safety climate and job stress among wildland fire fighters. At the time of our visits, the facility had five state agency fire crews: two Hotshot crews (each with 23 members); an Initial Attack crew (21 members); an Engines crew (6 members); and a Handcrew (20 members). At the time of our visits, all crews completed fuel reduction projects when not engaged in fire suppression. Crews from this program participated in fuel reduction projects when not engaged in fire suppression or training. Aside from being a good forestry management practice, these projects protect developed areas against wildfires by removing fuel so that, if a wildfire occurs, it is more easily contained and suppressed [National Park Service 2017]. While completing projects, fire fighters worked in groups of two to thin trees, remove underbrush, and limb trees using handheld chain saws. Cut material was run through a wood chipper or piled and burned during the winter months. Projects consisted of either a local daily commute or camping field project completed during four 10-hour days. Crews could set up remote field camps and were subject to primitive living conditions. The crews took their fire fighting equipment to these camps and were on call for fire assignments as they arose.

Crew definitions and job descriptions:

- Hotshot crew: highly skilled and specialized hand crews usually used in rugged terrain and difficult areas

- Hand crew: wildland and prescribed burns - construct fire lines, burnout and mop-up activities

- Initial attack crew: initial attack on a fire

- Engines crew: fire suppression using specialized fire engines and support activities

- Swamper: assist sawyers. Clear brush, limbs, and smaller trees

- Sawyer: saw timber - specialized training in cutting taller trees and those trees that have partially fallen and are in hazardous configurations

For more wildland fire information and definitions, see https://www.nwcg.gov/about-thenwcg-glossary-of-wildland-fire and https://firejobs.doi.gov/index.php?action=crews.

Wildland fire fighters engage in year-round activities to prevent or minimize spread of wildfires in addition to their role in containing active wildfires during the traditional March through October fire season. One of the primary activities for wildfire prevention is removing or reducing the amount of available vegetation that a wildfire could use as fuel. These fuel reduction activities may include removal of brush near structures, performing a controlled burn to create a "fuel free" zone around inhabited areas as a buffer, etc. Chain saws are a central tool used to complete many wildland fire fighter tasks including cutting down small trees, removal of fallen logs blocking access trails, or stripping limbs off logs so that they can be safely placed into a wood chipper, etc.

Use of chain saws, wood chippers, leaf blowers, and other power tools used by wildland 
fire fighters may place them at risk for exposure to hand-transmitted vibration, wood dust, $\mathrm{CO}$, and noise. Even fire fighters not personally operating handheld power tools and wood chippers may be exposed to noise, $\mathrm{CO}$, and wood dust by working nearby when those tools are in use. Since chain saws are such an important tool, all wildland fire fighters are required to complete the National Wildfire Coordinating Group S-212 Wildland Fire fighter Chain Saws course as part of their entry level training. Some wildland fire fighters, called sawyers, get additional specialty training to safely bring down taller trees and trees partially fallen that have "hung up" in hazardous configurations. The sawyer certification system has 3 levels: beginner, intermediate, and advanced. The higher the certification level, the larger the trees and the more complex configuration of trees certified individuals are qualified to handle. Sawyers often use chain saws with larger blades that require larger motors, which could result in higher noise, hand-transmitted vibration, and $\mathrm{CO}$ exposures.

We visited the facility headquarters at the beginning of the fire season in May 2015 and again at the end of the season in October 2015. During the first visit in May 2015, we conducted confidential medical interviews with fire fighters that covered work organization issues and occupational history. At the beginning of the season, most fire fighters were engaged in training activities, administrative tasks, and preparing for the season. When we visited at the end of the season, the fire fighters were engaged in season closeout procedures, making sure equipment was accounted for, and other administrative tasks. During the October 2015 visit, we conducted follow-up interviews on work organization issues to compare to pre-season. We released an interim report regarding safety climate, job stress, psychosocial factors at work, and sleep in May 2016. Overall, wildland fire fighter employees reported a strong safety climate, favorable perceptions of various psychosocial factors at work, and moderate job stress. Employees reported decreased sleep quality at the end of the season. The interim report can be found in Appendix B.

We returned in April 2016 to evaluate exposures during a fuel reduction project. During this visit, we evaluated $\mathrm{CO}$, wood dust, noise, and hand-transmitted vibration. Fire fighters also completed questionnaires covering work history and current tasks. We sent the agency and fire fighters notification letters with exposure monitoring results for CO in May 2016, for wood dust in June 2016, and for noise in November 2017.

\section{Methods}

The objectives of this health hazard evaluation were:

- Evaluate fire fighters' exposures to CO, wood dust, noise, and hand-transmitted vibration to identify opportunities for exposure reduction.

- Determine if fire fighters had signs and/or symptoms of CO poisoning, wood dust allergy, hearing loss, or hand-arm vibration syndrome (HAVS) and if so, was there a relationship between these conditions and duration of work and/or specific tool use.

- Determine if fire fighters reported diagnoses of CO poisoning or wood dust allergy since starting work at this facility. 
- Assess fire fighters' perceptions of safety climate, job stress, and psychosocial factors at work and screen for sleep problems.

- Evaluate fire fighters' self-reported average sleep duration, quality of sleep, and frequency of unintentional sleep episodes.

\section{Carbon Monoxide}

During the April 2016 site visit, we measured CO air concentrations in the breathing zone of fire fighters using direct reading BW Technologies GasAlert Extreme single gas meters. The instruments had a detection range of $0-1,000$ parts per million $(\mathrm{ppm})$ and data-logged $\mathrm{CO}$ measurements every 5 seconds. A brief description of occupational exposure limits (OELs) and health effects for $\mathrm{CO}$ is provided in Appendix A.

\section{Wood Dust}

We measured wood dust in the breathing zone of fire fighters during the April 2016 site visit using 37-millimeter diameter tared polyvinyl chloride filters with Accucap inserts. Air sampling pumps were calibrated to a flow rate of 2.0 liters per minute. Samples were analyzed using National Institute for Occupational Safety and Health (NIOSH) Method 0600 [NIOSH 2019]. A brief description of OELs and health effects for wood dust is provided in Appendix A.

\section{Noise and Hearing Conservation}

We measured fire fighters' personal noise exposures during the April 2016 site visit using Larson Davis Spark ${ }^{\mathrm{TM}}$ model 706RC integrating noise dosimeters. The dosimeters integrated noise at a 50-hertz $(\mathrm{Hz})$ sampling rate (50 measurements per second) and data-logged 5 -second averaged noise levels for the duration of the measurement period. Fire fighters wore dosimeters on their waistband, and we attached the dosimeter microphone on their outer clothing in an upright position midway between the neck and the edge of their shoulder. We covered the microphone with a windscreen to reduce artifact noise caused by the wind or by accidental bumping or rubbing. At the end of the work shift, we downloaded the noise measurement data from the dosimeters using the PCB Piezotronics Blaze ${ }^{\mathrm{TM}}$ software. The dosimeters simultaneously collected noise data using three different settings to allow comparison of noise measurement results with three different noise exposure limits, the NIOSH recommended exposure limit (REL), the Occupational Safety and Health Administration (OSHA) permissible exposure limit (PEL), and the OSHA action level (AL). Noise exposure limits are meant to be the amount of noise that most fire fighters can be exposed to without substantial risk of hearing loss. Additional information on noise exposure limits and health effects is provided in Appendix A.

We used Larson Davis Model 831 integrating sound level meters and frequency analyzers to measure sound levels and one-third octave band noise frequency levels (i.e., measurement of noise levels across 30 different frequencies). For most measurements we held the instrument or used a tripod at a height of approximately 5 feet above ground level and within 3-6 feet of the fire fighters or the primary noise source. 
We reviewed the hearing conservation program, including hearing protection, training, and audiometric testing. We obtained a print-out of audiograms from 2012 to 2015 for 69 current fire fighters. Audiometric testing had been completed yearly by an external provider. For fire fighters with a baseline and at least one subsequent audiogram, we assessed whether there was evidence of a hearing threshold shift, on the basis of OSHA and NIOSH criteria.

\section{Hand-transmitted Vibration from Chain Saws}

During the April 2016 visit, we measured fire fighters' exposures to hand-transmitted vibration during simulated fuel reduction operations. Two chain saw operators used four different Stihl ${ }^{\circledR}$ professional chain saw models to cut logs into slices as shown in Figure 1. Both operators were right-handed. The saws were used but well-maintained. Each operator completed five, 20-second sawing trials with each chain saw model.

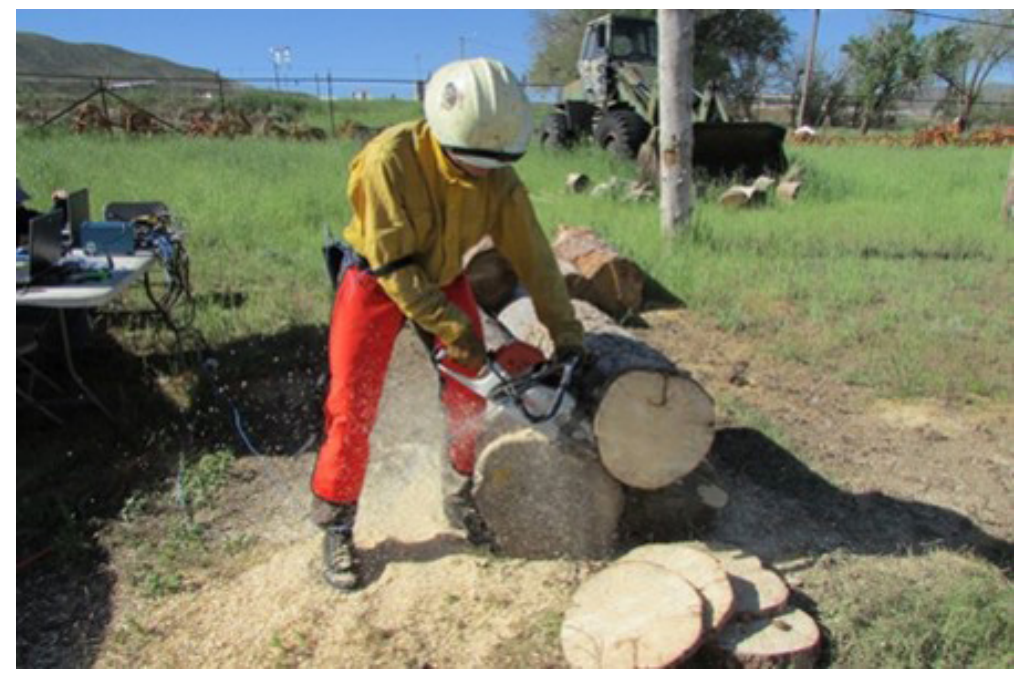

Figure 1. Sawyer cuts slices from logs while the vibration is measured at the hand-handle interface. Photo by NIOSH.

We evaluated chain saw vibrations by measuring the acceleration simultaneously at both handles in close proximity to where the vibration entered the operator's left and right hands in accordance with the International Organization for Standardization (ISO) ISO 5349-2, 2001 [ISO 2001b] and the American National Standards Institute (ANSI) ANSI S2.70-2006 [ANSI 2006]. To examine how the frequency weighting affected the results, the chain saw vibrations were evaluated based on band-limited unweighted acceleration as well as by frequency-weighted acceleration, as recommended by NIOSH [NIOSH 1989]. Although leaf blowers and other handheld power tools may produce vibrations that can be transmitted up to the operator, the chain saw was the only tool for which a quantitative assessment of vibration was conducted for this evaluation.

Figure 2 shows accelerometers mounted on the front and rear handles of one of the chain saws. All chain saw vibration measurements were collected via PCB Model 356B11 piezoelectric tri-axial accelerometers. The accelerometers were installed on mounting blocks and secured to the handles with hose clamps. Additional details about the vibration measurements and data are provided in Appendix A. 


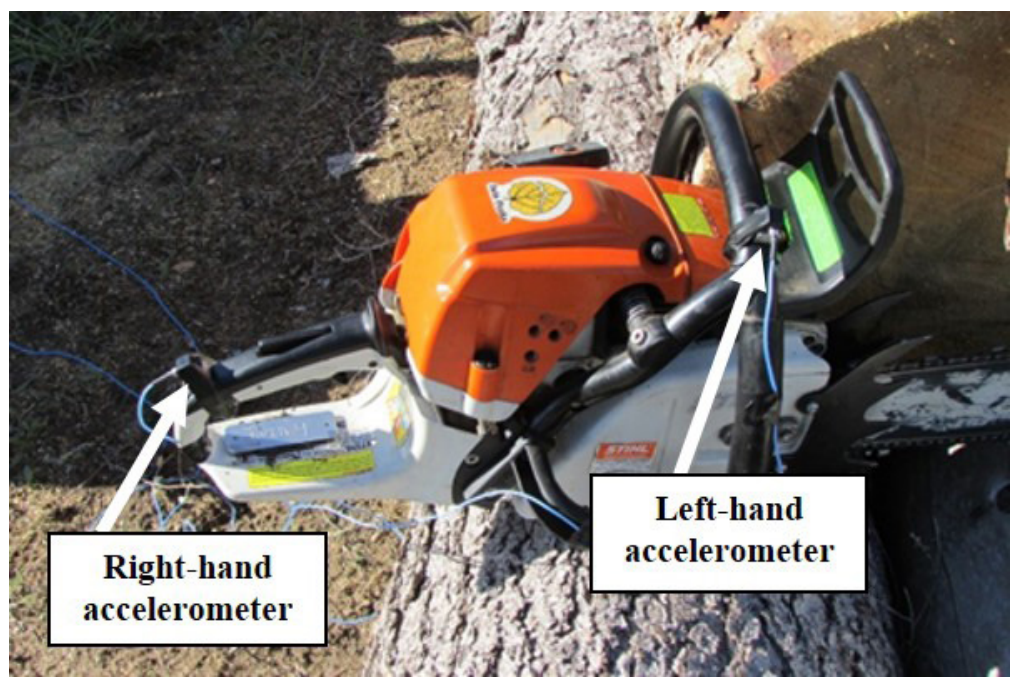

Figure 2. White arrows point to the two tri-axial accelerometers used to measure the acceleration at the hand-handle interface for right hand (rear handle) and the left hand (front handle). Photo by NIOSH.

\section{Medical Assessment}

\section{Confidential Medical Interviews}

We held confidential interviews with all of the fire fighters on duty to assess safety climate, job stress, psychosocial factors at work, and sleep during the May (pre-season; $\mathrm{n}=56$ ) and October (post-season; $n=48$ ) 2015 visits. Details about these methods and findings can be found in the interim report (provided in Appendix B) from May 2016.

\section{Questionnaire}

During the May 2016 visit, all 93 wildland fire fighters of the 5 crews based at this facility were invited to complete a one-time paper questionnaire. The questionnaire covered work history as both paid and volunteer fire fighter, current crew assignment, power tool use, and tasks. The questionnaire also included screening questions for hearing loss, HAVS, wood dust allergy, and CO poisoning since starting work at this facility. The questionnaire also reviewed participant knowledge of annual audiometric testing conducted by this facility as part of its hearing conservation program.

We assessed symptoms of hearing trouble in all participants with a set of 3 screening questions that were modified from others tools [National Center for Health Statistics 2014]. A positive response to the first question "Do you have trouble hearing/understanding when people speak to you in a room with background noise (i.e., other talking, TV, conversation in a restaurant, etc.)?", was defined as mild hearing trouble. Positive answers to either or both of the second or third questions was defined as moderate hearing trouble. The second hearing screening question was "Do you have trouble hearing/understanding when people speak to you in a quiet room?" and the third question was "Do people often ask you to turn down the volume on the TV?"

We also analyzed a subset of the hearing questions among returning fire fighter participants. We defined a returning fire fighter as one who reported their total years as a fire fighter at this facility as $\geq 1$ year. We did this subset analysis to identify hearing trouble that could possibly be related to use of loud power tools commonly used in wildland fire fighting over more than a single fire season. 
We assessed symptoms that could be consistent with HAVS via a panel of screening questions derived from the British Hand Arm Vibration Initial Screening Questionnaire. This questionnaire is traditionally used to determine if an employee should be referred for additional testing in order to confirm a diagnosis of HAVS [Health and Safety Executive 2018]. In our evaluation, fire fighters were defined as having symptoms that could be consistent with HAVS if they had a positive response to one or more of the following screening questions. All participants were asked if in the past year they ever:

- Had tingling of the fingers lasting more than 20 minutes after using vibrating equipment (i.e., chain saw or other power tools)?

- Had tingling of the fingers at any other time?

- Woke at night with pain, tingling or numbness in your hand or wrist?

- Had numbness in your fingers lasting more than 20 minutes after using a power tool?

- Had one or more of your fingers go numb more than 20 minutes after using vibrating equipment (i.e., chain saw or other power tools)?

- Had your fingers gone white on cold exposure?

- Had your fingers go white any other time?

- Had any other problems with the muscles or joints of the hands or arms?

- Had difficulty picking up very small objects (i.e., screws or buttons) or opening tight jars?

We used two screening questions that were derived from the European Community Respiratory Health Survey to evaluate participants for asthma [Grassi et al. 2003]. Participants were classified as having "asthma-like" symptoms if they answered positively to at least one of the screening questions. The screening questions were "Have you had wheezing or whistling in your chest at any time in the last 12 months?" and "Have you been woken up with a feeling of tightness in your chest at any time in the last 12 months?" Participants were asked to exclude symptoms that were present when they had a cold during this period. Additional questions were asked to determine possible work and wood dust relatedness of any asthma symptoms.

Exposure to wood dust may result in a rash in allergic individuals so participants were asked "In the past year, have you ever had a rash that started after handling wood?" CO exposure was assessed by asking participants if they had ever been diagnosed with $\mathrm{CO}$ poisoning since starting work at this facility or if they had experienced $\mathrm{CO}$ exposure related symptoms of headache, nausea/vomiting, lightheadedness/dizziness, or difficulty concentration while using gasoline or diesel powered equipment to perform job tasks.

We used SAS Version 9.3 (SAS Institute Inc.) for our statistical analyses. We calculated descriptive statistics including medians, ranges, frequencies, and percentages. A two-sample t-test was used to compare means for variables with normal distributions while the Wilcoxon two-sample test was used to compare means between variables that did not appear to have normal distributions. We compared mean age, years as a fire fighter, and use of various tools in the preceding 8 weeks of the second site visit for those with and without symptoms consistent with HAVS. These same tests were also used to compare mean age, mean years as a fire fighter, 
and mean hours of daily use of a chain saw and wood chipper for those returning fire fighters with and without hearing trouble and those with and without rash. To account for potential hearing trouble from proximity exposures, we also did similar comparison of HAVS symptom reports with fire fighter mean age and years worked as a fire fighter for those participants who did not report personally using power tools or equipment in the previous 8 weeks. $P$ values less than 0.05 were considered statistically significant. For tests with significant $P$ values, prevalence ratios with their 95\% confidence interval limits were reported.

\section{Results}

\section{Carbon Monoxide}

Results of personal air sampling for CO are provided in Table 1. Fire fighters' full-shift time-weighted average (TWA) exposures to $\mathrm{CO}$ were $2.5-9.6 \mathrm{ppm}$, which were well below full-shift OELs. However, each of the fire fighters had brief, intermittent $\mathrm{CO}$ exposures above the NIOSH ceiling limit of $200 \mathrm{ppm}$. The total time fire fighters exceeded the NIOSH ceiling ranged from 0.25-2.3 minutes. No fire fighter exceeded the NIOSH ceiling for more than 25 seconds in any single occurrence of exceedance. No exposures were above the NIOSH immediately dangerous to life and health (IDLH) level of 1,200 ppm.

Table 1. Full-shift TWA personal air sampling results for CO, April 2016

\begin{tabular}{|c|c|c|c|c|}
\hline Employee & $\begin{array}{l}\text { Sample } \\
\text { duration } \\
\text { (minutes) }\end{array}$ & $\begin{array}{l}\text { Range of } \\
\text { exposure } \\
\text { (ppm) }\end{array}$ & $\begin{array}{l}\text { Total time above } \\
\text { NIOSH ceiling limit } \\
\text { (minutes) }\end{array}$ & $\begin{array}{l}\text { Concentration } \\
\text { (ppm) }\end{array}$ \\
\hline Fire fighter 1 - day 1 & 473 & 0-249 & 0.25 & 4.7 \\
\hline Fire fighter $2-$ day 1 & 467 & $0-220$ & 0.33 & 3.0 \\
\hline Fire fighter 3 - day 1 & 464 & $0-712$ & 0.83 & 7.2 \\
\hline Fire fighter $4-$ day 1 & 464 & $0-428$ & 1.5 & 6.2 \\
\hline Fire fighter $5-$ day 1 & 469 & $0-467$ & 1.3 & 5.3 \\
\hline Fire fighter $1-$ day 2 & 601 & $0-384$ & 0.92 & 6.5 \\
\hline Fire fighter $2-$ day 2 & 583 & $0-403$ & 0.50 & 2.5 \\
\hline Fire fighter $3-$ day 2 & 595 & $0-450$ & 2.1 & 9.6 \\
\hline Fire fighter $4-$ day 2 & 583 & $0-466$ & 1.8 & 5.0 \\
\hline Fire fighter $5-$ day 2 & 588 & $0-568$ & 2.3 & 4.9 \\
\hline ACGIH TLV (8-hour TWA) & & & & 25 \\
\hline NIOSH REL (10-hour TWA) & & & & 35 \\
\hline NIOSH Ceiling & & & & 200 \\
\hline OSHA PEL (8-hour TWA) & & & & 50 \\
\hline
\end{tabular}

$A C G I H \otimes=$ American Conference of Governmental Industrial Hygienists

TLV® $=$ Threshold limit value 
Figure 3 provides a time-history showing real-time $\mathrm{CO}$ exposures for fire fighter 5 on day 2. Intermittent exposures can be seen exceeding the NIOSH ceiling limits. The highest exposures occurred when using the chainsaw (as seen in the fire fighter in Figure 3), but we noted a slight decrease in exposures when fire fighters rotated to the swamping task. Fire fighters had no $\mathrm{CO}$ exposures during breaks and lunch.

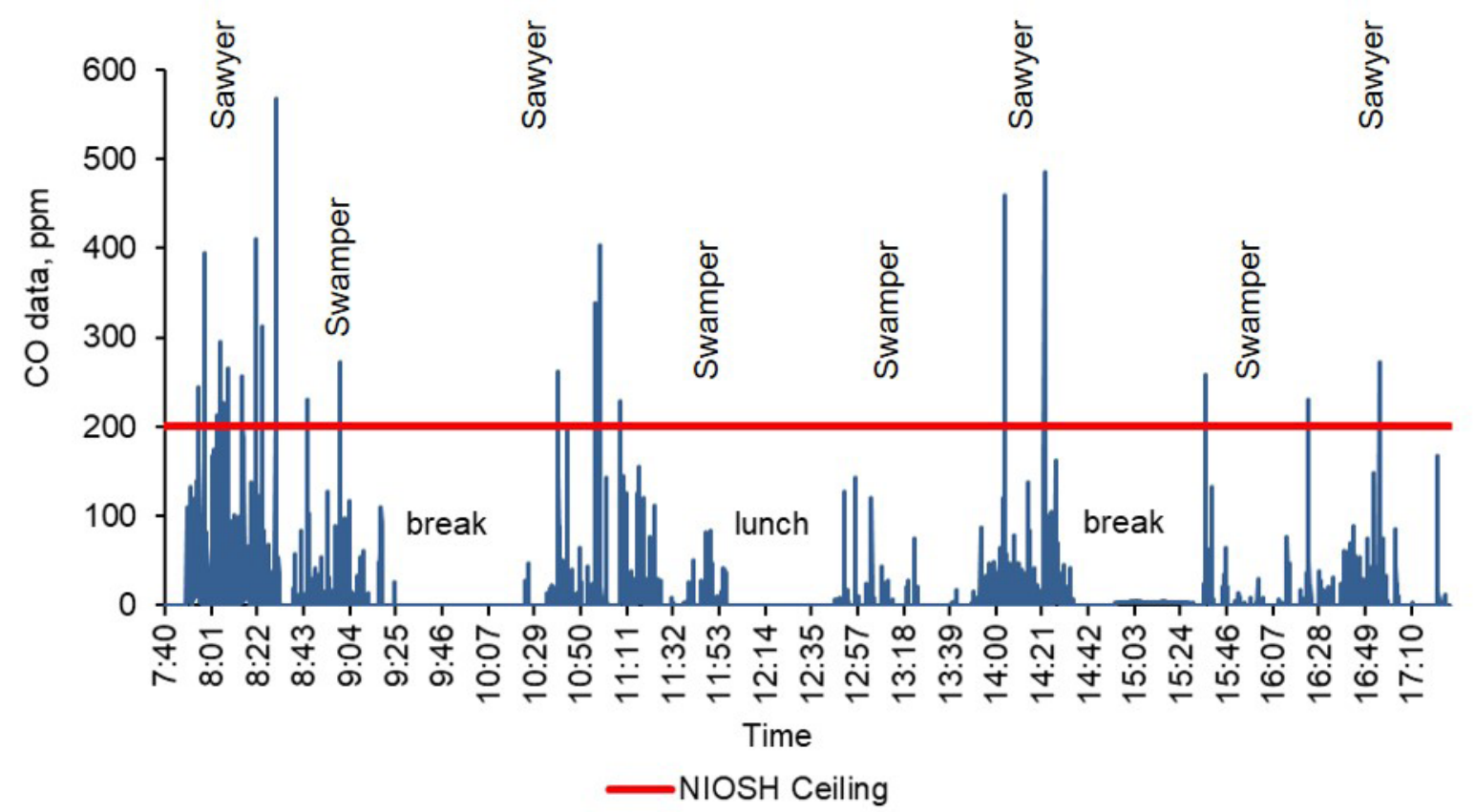

Figure 3. Time-history showing real-time CO measurement results for fire fighter 5 during day 2.

\section{Wood Dust}

Personal air sampling results for wood dust are provided in Table 2. One sample (fire fighter 2 - day 2) was lost in the brush and debris during sample collection. Fire fighters' exposures to wood dust in the air were $0.87-2.0$ milligrams per cubic meter $\left(\mathrm{mg} / \mathrm{m}^{3}\right)$. Six of the nine samples were above the NIOSH REL and ACGIH TLV of $1.0 \mathrm{mg} / \mathrm{m}^{3}$. OSHA does not have a PEL specific for wood dust but compares exposures to their PEL of $15 \mathrm{mg} / \mathrm{m}^{3}$ (inhalable fraction) for particles not otherwise regulated. 
Table 2. Personal air sampling for wood dust, April 2016

\begin{tabular}{lcc}
\hline Employee & $\begin{array}{c}\text { Sample } \\
\text { duration } \\
\text { (minutes) }\end{array}$ & $\begin{array}{c}\text { Concentration } \\
\left(\mathrm{mg} / \mathrm{m}^{3}\right)\end{array}$ \\
\hline Fire fighter 1 - day 1 & 473 & 0.87 \\
Fire fighter 2 - day 1 & 442 & 1.2 \\
Fire fighter 3 - day 1 & 464 & 1.1 \\
Fire fighter 4 - day 1 & 464 & 1.8 \\
Fire fighter 5 - day 1 & 466 & 0.97 \\
Fire fighter 1 - day 2 & 597 & 1.7 \\
Fire fighter 3 - day 2 & 596 & 2.0 \\
Fire fighter 4 - day 2 & 593 & 0.89 \\
Fire fighter 5 - day 2 & 589 & 1.2 \\
\hline NIOSH REL & & 1.0 \\
ACGIH TLV & & $1.0^{*}$ \\
OSHA PEL & & $15 \dagger$ \\
\hline
\end{tabular}

*Wood dust, species other than western red cedar

†Particulates not otherwise regulated (inhalable fraction)

\section{Noise}

Full shift personal noise exposure measurement results are provided in Table 3. All five fire fighters' noise exposures were above the OSHA AL and NIOSH REL on both days of monitoring. All fire fighters, except fire fighter 2, were also exposed to noise above the OSHA PEL on one or both days of monitoring. Fire fighter 2 had supervisory duties and spent slightly less time using the chain saw compared to other fire fighters on the crew.

Table 3. Fire fighters full-shift TWA personal noise exposures, May 2016

\begin{tabular}{lcccc}
\hline Employee & $\begin{array}{c}\text { Measurement } \\
\text { duration } \\
\text { (minutes) }\end{array}$ & $\begin{array}{c}\text { Results based } \\
\text { on OSHAAL } \\
\text { criterion (dBA) }\end{array}$ & $\begin{array}{c}\text { Results based } \\
\text { on OSHA PEL } \\
\text { criterion (dBA) }\end{array}$ & $\begin{array}{c}\text { Results based } \\
\text { on NIOSH REL } \\
\text { criterion (dBA) }\end{array}$ \\
\hline Fire fighter 1 - day 1 & 473 & 89.6 & 88.8 & 95.1 \\
Fire fighter 2 - day 1 & 442 & 86.4 & 85.5 & 91.9 \\
Fire fighter 3 - day 1 & 464 & 92.1 & 91.5 & 97.1 \\
Fire fighter 4 - day 1 & 464 & 94.8 & 94.5 & 99.2 \\
Fire fighter 5 - day 1 & 466 & 90.9 & 90.3 & 95.6 \\
Fire fighter 1 - day 2 & 597 & 92.4 & 91.7 & 97.1 \\
Fire fighter 2 - day 2 & 582 & 87.8 & 86.8 & 92.8 \\
Fire fighter 3 - day 2 & 596 & 95.2 & 94.8 & 99.3 \\
Fire fighter 4 - day 2 & 593 & 94.3 & 93.9 & 98.8 \\
Fire fighter 5 - day 2 & 405 & 93.4 & 92.9 & 98.1 \\
\hline Noise exposure limits (8-hour work shift) & 85.0 & 90.0 & 85.0 \\
Noise exposure limits (10-hour work shift) & 83.4 & 90.0 & 84.0 \\
\hline
\end{tabular}

$\mathrm{dBA}=$ decibels, $\mathrm{A}$-scale 
Figure 4 provides the noise exposure time-history profile for fire fighter 5 on the second day of noise monitoring. While actively using the chain saw, noise exposure reached $110 \mathrm{dBA}$. Noise exposures during swamping were slightly less, reaching up to $100 \mathrm{dBA}$.

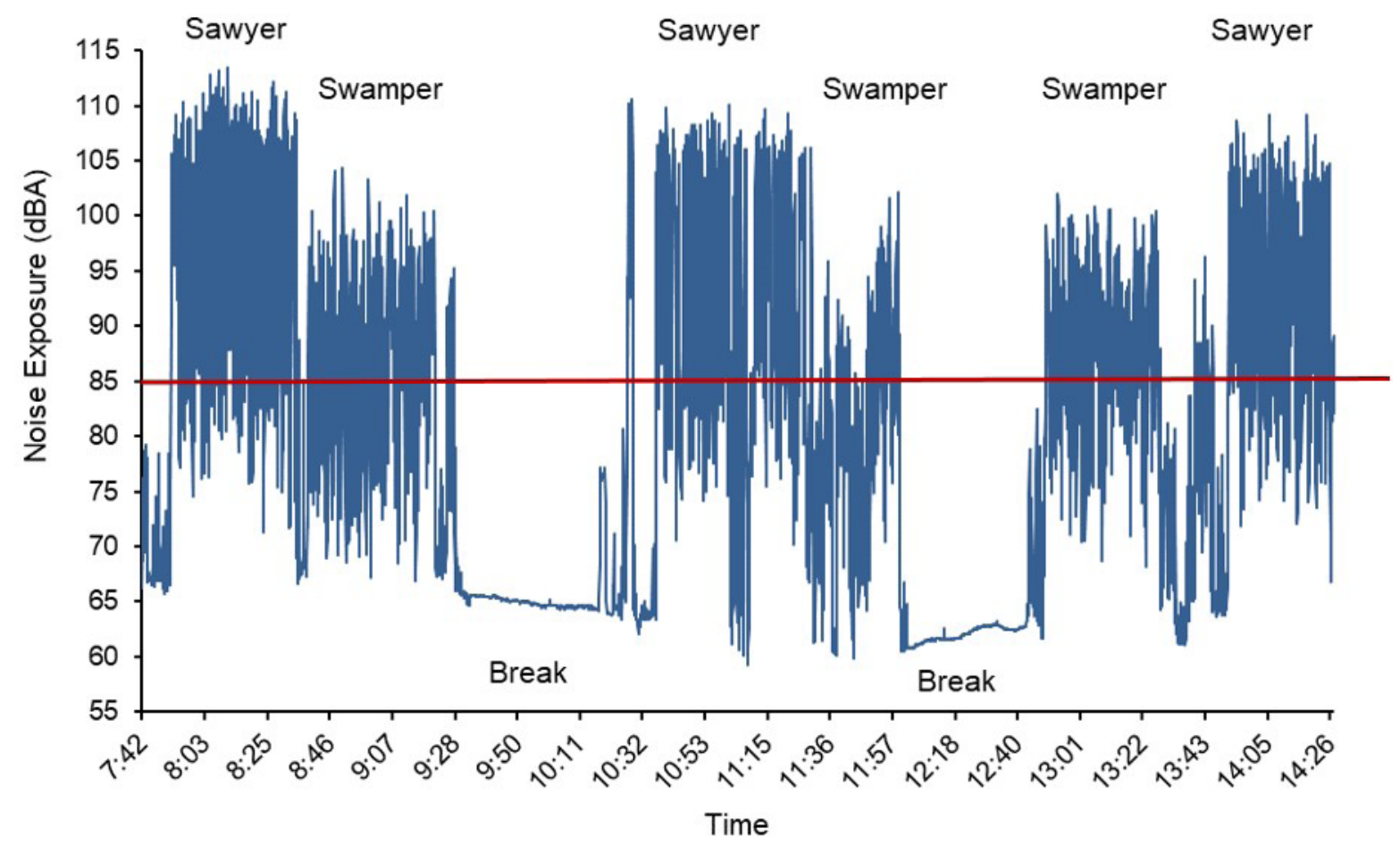

Figure 4. Noise exposure time-history profile for fire fighter 5 during day 2 . The line across the figure at $85 \mathrm{dBA}$ denotes the NIOSH REL.

The range of sound levels during chain saw use was 93.5-103.8 dBA (Table 4). We did not find a notable difference in sound levels between the different types of chain saws used by fire fighters: Stihl Rollomatic ${ }^{\circledR}$ ES Model 440, Stihl Model MS362, and Stihl Model MS461. Sound levels were slightly higher overall when cutting larger diameter logs versus cutting down small oak trees and serviceberry bushes or cutting brush piles. Sound levels near fire fighters engaged in swamping tasks were similar, ranging 91.8-99.8 dBA. 
Table 4. Task-based sound levels during chain saw use

\begin{tabular}{lcc}
\hline Task & $\begin{array}{c}\text { Number of } \\
\text { measurements }\end{array}$ & $\begin{array}{c}\text { Sound level } \\
(\mathrm{dBA})\end{array}$ \\
\hline $\begin{array}{l}\text { Operator using chain saws } \\
\text { to cut small oak trees or } \\
\text { serviceberry bushes }\end{array}$ & 5 & $93.5-99.8$ \\
$\begin{array}{l}\text { Using chain saws to cut } \\
\text { brush piles }\end{array}$ & 5 & $95.6-101.2$ \\
$\begin{array}{l}\text { Using chain saw to cut } \\
\text { oak logs }\end{array}$ & 6 & $98.9-103.8$ \\
$\begin{array}{l}\text { Swamping - nearby chain } \\
\text { saw operator was cutting } \\
\text { brush piles or small } \\
\text { oak trees }\end{array}$ & 3 & $91.8-99.8$ \\
\hline
\end{tabular}

Short duration personal noise exposure measurements were near or slightly above $100 \mathrm{dBA}$ (based on NIOSH measurement criterion) when trainees operated, fed, or pulled brush to the chipper (Table 5). Noise exposures ranged 88-94 dBA when trainees observed and used chain saws for short periods. However, the instructor's noise exposure was below $80 \mathrm{dBA}$ when instructing or observing trainees using a chain saw.

Table 5. Task-based personal noise exposures during training session activities, May 2016

\begin{tabular}{|c|c|c|c|c|}
\hline Training activity & $\begin{array}{l}\text { Measurement } \\
\text { duration } \\
\text { (minutes) }\end{array}$ & $\begin{array}{l}\text { Results based } \\
\text { on OSHA AL } \\
\text { criterion (dBA) }\end{array}$ & $\begin{array}{l}\text { Results based } \\
\text { on OSHA PEL } \\
\text { criterion (dBA) }\end{array}$ & $\begin{array}{l}\text { Results based } \\
\text { on NIOSH REL } \\
\text { criterion (dBA) }\end{array}$ \\
\hline Operating chipper & 31 & 97.7 & 97.6 & 100.0 \\
\hline Feeding chipper & 32 & 97.8 & 97.7 & 100.4 \\
\hline Pulling brush to chipper & 29 & 97.2 & 97.1 & 99.5 \\
\hline $\begin{array}{l}\text { Instructor: teaching and } \\
\text { observing trainees using } \\
\text { a chain saw }\end{array}$ & 122 & 67.9 & 21.7 & 74.9 \\
\hline $\begin{array}{l}\text { Trainee } 1 \text { : observing and } \\
\text { using a chain saw }\end{array}$ & 87 & 85.0 & 84.1 & 93.6 \\
\hline $\begin{array}{l}\text { Trainee } 2 \text { : observing and } \\
\text { using a chain saw }\end{array}$ & 92 & 84.2 & 83.4 & 93.0 \\
\hline $\begin{array}{l}\text { Trainee 3: observing and } \\
\text { using a chain saw }\end{array}$ & 40 & 82.8 & 81.0 & 88.2 \\
\hline
\end{tabular}




\section{Hearing Conservation Program}

All fire fighters were included in the agency's hearing conservation program. Baseline and annual audiometric testing was done by an external audiometric test contractor via a mobile test van, typically in the fall. Prior to audiometric testing, the audiometric test contractor asked fire fighters several screening "yes/no" questions regarding current and permanent hearing history. Testing was done at the following audiometric frequencies 500, 1000, 2000, $3000,4000,6000$, and $8000 \mathrm{~Hz}$. After testing, the contractor provided the fire fighter a summary of their test results and provided the agency a summary report of overall results and a print-out of individual audiometric test history results.

The safety and health director and audiometric test provider conducted hearing conservation training. The safety and health director also did hearing protection fit testing using the FitCheck Solo ${ }^{\text {TM }}$ system. Fire fighters were provided with a choice of five different types of insert type hearing protectors: $3 \mathrm{M}^{\mathrm{TM}} \mathrm{E}-\mathrm{A}-\mathrm{R} s o f \mathrm{fT}^{\mathrm{TM}}, 3 \mathrm{M}$ E-A-R ${ }^{\mathrm{TM}}$ Classic ${ }^{\mathrm{TM}}$ SuperFit $^{\mathrm{TM}}$ 33; Howard Leight ${ }^{\mathrm{TM}}$ Max ${ }^{\circledR}$, Howard Leight Max Lite ${ }^{\circledR}$, and Howard Leight FirmFit ${ }^{\circledR}$. One of the fire fighters doing fuel reduction wore self-purchased banded earplugs, instead of the agency-provided plugs. We observed that these plugs were very dirty.

\section{Hand-transmitted Vibration from Chain Saws}

Table 6 presents the five-trial acceleration means for each of the saw operator/saw model combinations. The results for the two operators were similar. The acceleration measured at the right hand (rear handle) was consistently higher than that for the left hand (front handle). The average frequency-weighted acceleration value for the right hand was 8.4 meters per second squared $\left(\mathrm{m} / \mathrm{s}^{2}\right)$. Chain saw model MS 440 exhibited the highest vibration at both hands for both operators.

Table 6. Unweighted and frequency-weighted acceleration means for each operator and chain saw model

\begin{tabular}{lccccc}
\hline & & \multicolumn{2}{c}{$\begin{array}{c}\text { Unweighted } \\
\left(\mathrm{m} / \mathrm{s}^{2}\right)\end{array}$} & \multicolumn{2}{c}{$\begin{array}{c}\text { Weighted } \\
\left(\mathrm{m} / \mathrm{s}^{2}\right)\end{array}$} \\
\hline Sawyer & Model & Left & Right & Left & Right \\
Operator 1 & MS362 & 84.1 & 124.1 & 3.6 & 6.4 \\
& MS440 & 82.8 & 148.2 & 6.0 & 11.0 \\
& MS460 & 73.1 & 124.1 & 5.2 & 8.6 \\
Operator 2 & MS461 & 65.0 & 121.6 & 4.8 & 9.3 \\
& MS362 & 83.9 & 110.0 & 4.8 & 6.0 \\
& MS440 & 93.0 & 138.1 & 7.0 & 10.2 \\
& MS460 & 68.4 & 98.6 & 5.1 & 7.2 \\
& MS461 & 63.3 & 112.3 & 4.5 & 8.2 \\
\hline
\end{tabular}


Table 7 presents the estimated times that an operator could use each saw during a work shift before reaching the ANSI S2.70 [ANSI 2006] daily exposure action value (DEAV) or daily exposure limit value (DELV). Because the exposures are higher for the rear handle than the front handle, these time values are based on the right-hand average frequency-weighted acceleration. The average time to reach the DEAV for the four saws was about 45 minutes. The average time to reach the DELV was less than 3 hours.

Table 7. Estimated time an operator could use each chain saw model during a workshift before reaching DEAV and DELV

\begin{tabular}{lcc}
\hline Saw & $\begin{array}{c}\text { Time to reach DEAV } \\
\text { (hours) }\end{array}$ & $\begin{array}{c}\text { Time to reach DELV } \\
\text { (hours) }\end{array}$ \\
\hline MS362 & 1.3 & 5.2 \\
MS440 & 0.4 & 1.8 \\
MS461 & 0.8 & 3.2 \\
MS461 & 0.7 & 2.6 \\
\hline
\end{tabular}

\section{Medical Questionnaire}

In total, 89 (96\%) of 93 wildland fire fighters of the 5 crews based at this facility completed the medical questionnaire during the May 2016 site visit. All participants were male with a median age of 27 years (range: 19-42 years). The median number of total years worked at this facility was 3.6 years (range 1 day-13.3 years). Of the $89,59(66 \%)$ participants had worked at this facility for one or more years. This subset of participants are noted as returning fire fighters. Most participants' fire fighting work history consisted solely of wildland fire fighting. Only $9(10 \%)$ reporting any work history of structural fire fighting, ranging from 11 months to 6.25 years. In addition to the basic chain saw training, 38 (43\%) participants reported having crew roles that required sawyer certification.

Participants reported that their median workday length in the preceding 8 weeks was 10 hours (range: 8-16 hours) and that the median number of consecutive days worked was 4 (range 4-18 days). Participants were asked about the tools they used during their work in the past 8 weeks. Table 8 below shows the frequency and duration of use of various power tools commonly used in wildland fire fighting. Participants responding that they had used a specific tool were then asked to estimate the average hours that tool was used during a typical workday. Most (91\%) participants reported use of at least one of the following power tools in the previous 8 weeks: chain saw, leaf blower, wood chipper, hand-held wood boring drill, brush cutter, or pole pruner. 
Table 8. Reported tool use

\begin{tabular}{lcc}
\hline Tool & $\begin{array}{c}\text { Number (\%) of fire } \\
\text { fighters who reported } \\
\text { using tool [n = 89] }\end{array}$ & $\begin{array}{c}\text { Median hours tool } \\
\text { used during } \\
\text { workday }\end{array}$ \\
\hline Chain saw & $66(74)$ & 4.0 \\
Wood chipper & $59(66)$ & 4.0 \\
Leaf blower & $16(18)$ & 1.0 \\
Brush cutter & $6(7)$ & 2.0 \\
Hand drill & $4(5)$ & 3.7 \\
Pole pruner & 0 & Not applicable \\
Other* & $15(17)$ & 4.0 \\
\hline
\end{tabular}

${ }^{*}$ Other was a write-in category for tools not mentioned. Responses included non-powered hand tools such as the pulaski, slam, and combitool.

\section{Hearing Loss}

The questionnaire covered hearing protection device (HPD) use, hearing trouble as documented by positive responses to screening questions, and audiometric testing. The majority (94\%) of participants reported always using HPDs while working while $6 \%$ reporting using their HPDs only sometimes. All participants reported ear plugs as their only HPDs. No fire fighters reported using ear muffs. Sixty-seven (75\%) participants reported receiving formal training on the proper wear of HPDs since starting work at this facility. The hearing trouble screening questions responses showed that 49 (55\%) participants reported no subjective hearing trouble, as defined by answering no to all 3 screening questions. We identified $14(16 \%)$ participants as having mild hearing trouble and we identified $26(29 \%)$ participants as having moderate hearing trouble.

Seventy-one (80\%) participants reported having had a hearing test (also known as an audiogram). Of those 71 , the majority ( $86 \%$ ) stated the hearing test was done as part of the facility's hearing conservation program. No participants reported having a hearing test done because they were having trouble hearing. Of the 70 participants who answered the question regarding the findings of their previous hearing test, $34(49 \%)$ stated the test did not show any hearing loss, 23 (33\%) reported the test showed hearing loss, and $13(19 \%)$ responded that they did not know what their test showed.

For the subset of returning fire fighters, we did not find a significant relationship between subjective hearing trouble by questionnaire responses and total years worked as a fire fighter $(P=0.61)$ or age $(P=0.10)$. In addition, we did not find a statistically significant association between subjective hearing trouble and mean hours of chain saw use in the past 8 weeks $(P=0.92)$ or mean hours of wood chipper use $(P=0.82)$. We then included those who did not report any personal use of those two tools in the last 8 weeks to see if those working in the vicinity where these tools were being used were affected by their proximity even though they were not personally using these tools. We did not find a relationship between subjective hearing trouble and chain saw use $(P=0.55)$. However, we found that those who reported 
using a wood chipper in the previous 8 weeks were more likely to have subjective hearing trouble than those who did not use a wood chipper (54\% vs. $23 \%, P=0.03)$.

We reviewed audiometry results for the 69 fire fighters tested in 2015, the most recent year test results were available. Of the 69 fire fighters with audiometry results, 27 only had a baseline audiogram, and 42 had a baseline and at least one annual audiogram. Of the 42 with a baseline and an annual audiogram, one had an OSHA-defined standard threshold shift (STS); however, nine (21\%) had a NIOSH-defined significant hearing threshold shift. Their median age was 26 years (range: 19-57) and 94\% were male. One of these 69 fire fighters had a material hearing impairment as defined by NIOSH [NIOSH 1998], as well as severe hearing loss as defined by the American Speech-Language-Hearing Association (ASHA) [ASHA 2018]. In addition, three fire fighters had ASHA-defined moderately severe hearing loss and three had ASHA-defined moderate hearing loss. Of these six fire fighters, four reported moderate hearing trouble on the questionnaire, one reported mild hearing trouble, one reported no hearing trouble, and one did not complete a questionnaire. All six who completed the questionnaire reported using a chain saw in the previous 8 weeks and five of the six reported using the wood chipper in the previous 8 weeks. As part of their pre-screening process for the annual audiogram, fourteen $(20 \%)$ of the 69 fire fighters subjectively reported during pre-screening of having ringing or roaring in the ears.

\section{Hand-arm Vibration Syndrome Symptoms}

HAVS can result from working with hand-held power tools. We asked about other medical conditions that can result in similar symptoms of upper extremity pain, numbness, tingling, or weakness. The most common of these conditions among participants was hand or wrist tendonitis reported by $16 \%$ of respondents. One participant each reported having diabetes, rheumatoid arthritis, trigger finger, and ganglion cyst. One participant had a prior diagnosis of vibration white finger (VWF), which can occur as part of HAVS.

Ten questions covered signs and symptoms experienced in the past year. Sixty-five $(73 \%)$ of participants answered yes to one or more of these symptom questions that could be consistent with HAVS. Fifty participants (56\%) answered yes to two or more of the HAVS symptoms. All were recommended to obtain a follow-up evaluation by their healthcare provider for HAVS. Almost half (49\%) of the participants reported having had pain, aching, stiffness, burning, numbness, or tingling in their hands or wrists. Forty-two (47\%) participants reported being awoken at night with pain, tingling, or numbness in their hands or wrists and having tingling in their fingers not associated with power tool use. Table 9 lists all the HAVS screening questions and their responses. 
Table 9. Responses to HAVS screening questions

\begin{tabular}{lc} 
Question & $\begin{array}{c}\text { Number (\%) of participants } \\
\text { reporting symptom in the past } \\
\text { year [n = 89] }\end{array}$ \\
\hline $\begin{array}{l}\text { Pain, aching, stiffness, burning, numbness, or tingling in your } \\
\text { hands/wrists }\end{array}$ & $44(49)$ \\
$\begin{array}{l}\text { Tingling of the fingers at any other time (not within } 20 \text { minutes of } \\
\text { using a power tool) }\end{array}$ & $42(47)$ \\
$\begin{array}{l}\text { Awoken at night with pain, tingling or numbness in your hand or wrist } \\
\text { Tingling of the fingers lasting more than } 20 \text { minutes after using }\end{array}$ & $32(36)$ \\
vibrating equipment (i.e. chain saw or other power tools) & $26(29)$ \\
$\begin{array}{l}\text { Numbness in your fingers lasting more than } 20 \text { minutes after } \\
\text { using a power tool } \\
\text { Had one or more of your fingers go numb more than } 20 \text { minutes } \\
\text { after using vibrating equipment (i.e. chain saw or other power tools) } \\
\text { Had your fingers gone white on cold exposure } \\
\text { Had difficulty picking up very small objects (i.e., screws or }\end{array}$ & $26(29)$ \\
buttons) or opening tight jars & $19(21)$ \\
Had your fingers go white any other time & $14(16)$ \\
Any other problems with the muscles or joints of the hands or arms & $10(11)$ \\
\hline
\end{tabular}

Of the 44 participants who reported pain, aching, stiffness, burning, numbness or tingling in their hands/wrists in the past year, 26 (59\%) reported having these symptoms between once a week and once a month. When they had the symptom(s), the duration varied between less than an hour (32\%), between 1-24 hours (34\%), 25 hours to one week (27\%), and greater than one week (9\%). The discomfort was rated as mild $(61 \%)$, moderate $(30 \%)$, or not painful at all (9\%). Twenty-nine (66\%) participants noted they were using a chain saw at the time of first onset, and $3(7 \%)$ reported not using any tool around the time of first onset. Eleven $(25 \%)$ wrote in that they were using non-power tools such as the Pulaski, scraper, or combitool when their hand/wrist symptoms started. Two participants wrote in that the symptoms began as a result of non-work related trauma. Of the 44 with hand/wrist symptoms, most (64\%) said work tasks made the hand/wrist problem worse, and half reported having had this hand/wrist problem in the past 7 days. Despite these frequent and recent symptoms, most (93\%) reported not having seen a healthcare provider for this hand/wrist problem in the past year. None reported missing any work because of it, and only one reported requiring job transfer or task restriction due to the hand/wrist problem. All participants who reported symptoms that could be consistent with HAVS were advised to seek further evaluation by their healthcare provider.

We also analyzed the data for the 59 returning fire fighters to see if there was an association between reported HAVS symptoms and use of various tools in the preceding 8 weeks. We did not find a significant association between positive responses to the HAVS referral screening questions and use of a chain saw $(P=0.07)$, wood chipper $(P=0.84)$, brush cutter $(P=0.28)$, or hand drill $(P=0.62)$ in the previous 8 weeks. However, participants reporting one or more symptoms that could be consistent with HAVS were more likely to report use of a leaf blower in the previous 8 weeks than those without symptoms $(75 \%$ vs. $25 \%, P=0.02)$. 


\section{Wood dust, Asthma, and Carbon Monoxide}

Nine (10\%) participants reported an existing diagnosis of asthma. All were diagnosed by a healthcare provider, and none reported worsening of their asthma since starting work as a fire fighter at this facility. Eight of those with a preexisting asthma diagnosis reported being diagnosed as children with only one participant reported being diagnosed as an adult. The majority of participants $(84 \%)$ reported never having smoked. Twelve $(13 \%)$ reported being former smokers, and only $2(2 \%)$ identified as current smokers.

Of 88 participants who answered the asthma screening questions, 20 (23\%) participants were classified as having asthma-like symptoms by answering yes to one or both of the asthma screening questions. Their responses are shown in Table 10. Two participants answered yes to both questions.

Table 10. Responses to asthma screening questions

\begin{tabular}{lc}
\hline Screening question & $\begin{array}{c}\text { Number of positive } \\
\text { responses to the } \\
\text { screening question } \\
(\%)[\mathrm{n}=88]^{*}\end{array}$ \\
\hline $\begin{array}{l}\text { Have you had wheezing or whistling in } \\
\text { your chest at any time in the last } \\
12 \text { months? }\end{array}$ & $15(17)$ \\
Have you been woken up with a \\
feeling of tightness in your chest at \\
any time in the last 12 months?
\end{tabular}

${ }^{*}$ One participant did not answer the asthma screening questions

Only 5 (56\%) of the 9 participants with pre-existing asthma were among the 20 captured by the asthma screening questions. Of these 5, only one reported having an asthma attack in the past year. Of the 20 participants classified as having asthma-like symptoms, 16 were never smokers, 3 were former smokers, and 1 was a current smoker. All participants who reported these symptoms were advised to seek further evaluation by their healthcare provider.

Of 88 participants who responded to the question, 25 (28\%) participants reported developing a rash after handling wood in the last year. The rashes were reported all over the body and not predominantly on hands/arms. Only 7 (28\%) of the 25 participants who reported a rash with wood dust reported seeing a healthcare provider for it. Of these seven, six reported being diagnosed with either poison oak, poison ivy, or poison sumac while one was given a non-specific dermatitis diagnosis. We also found a significant positive association between increasing total years as fire fighter at this facility and reporting a rash related to wood dust exposure $(P=0.047)$. 
No participant reporting being diagnosed with $\mathrm{CO}$ poisoning since starting work at this facility. However, 33 (37\%) of the 89 participants reported experiencing at least one symptom that could be consistent with $\mathrm{CO}$ poisoning while operating gasoline/dieselpowered equipment on the job. The most common symptom reported was headache $(43 \%)$ followed by feeling dizzy or lightheaded (27\%), difficulty concentrating (16\%), and nausea and/or vomiting $(10 \%)$.

\section{Discussion}

In our evaluation we tested crews in a single state. Other state crews may use other equipment and have different levels of maintenance. Other types of wildland fire fighters, such as smokejumper and helitak crews were not part of this assessment so our results may not be applicable to these type of wildland fire fighters. In addition, our survey questions about symptoms that could be consistent with asthma and HAVS are non-specific. The questions were not meant to be diagnostic, and fire fighters reporting symptoms were advised to seek additional medical evaluation.

\section{Carbon Monoxide}

During our evaluation, average $\mathrm{CO}$ air concentrations measured on fire fighters were well below full-shift exposure limits. Because the work is done outdoors, air movement typically disperses $\mathrm{CO}$ from chain saw exhaust relatively quickly. However, all fire fighters had brief peak $\mathrm{CO}$ exposures exceeding the NIOSH ceiling limit. These elevated exposures were never more than 25 seconds in length during a single occurrence and occurred due to position of the fire fighter relative to prevailing wind currents, which at times would carry chain saw exhaust directly toward the fire fighter. CO may not diffuse when the air is still in the working environment [Hooper et al. 2017]. At times, fire fighters may be able to position themselves, relative to wind direction, so that exhaust blows away from them, but this may not always be possible, depending on safety considerations such as the lean of the tree they need to fell. We did not find differences in $\mathrm{CO}$ concentrations between the different chain saws, but researchers have measured higher levels of $\mathrm{CO}$ when chainsaws were running at high revolutions per minute [Lipoglavsek 2000]. None of the fire fighters reported CO poisoning, but some reported non-specific symptoms that could be consistent with $\mathrm{CO}$ exposures such as headaches and lightheadedness. Chronic exposures to low ambient $\mathrm{CO}$ concentrations have been reported to affect multiple body systems, and $\mathrm{CO}$ is one of the most common exposures encountered by fire fighters when responding to wildland fires. It is important to consider that wildland fire fighters may also be exposed to $\mathrm{CO}$ from burning materials during an actual fire response and when setting prescribed burns for fuel reduction projects.

\section{Wood Dust}

Air sampling results showed that fire fighters exposures to wood dust were above the NIOSH and ACGIH recommended OEL of $1.0 \mathrm{mg} / \mathrm{m}^{3}$. These exposures were similar to those measured in forestry workers in central Italy using chain saws [Marchi et al. 2017]. During our site visit, fire fighters were primarily cutting small oak trees; however, the kinds of trees or bushes fire fighters cut during fuel reduction can vary by location. We observed 
that at times, depending on prevailing wind speed, direction, and fire fighter position when using the chain saw, wood dust would blow toward fire fighters as they were cutting trees or brush piles. When possible, fire fighters should position themselves so that dust blows away from them. However, as noted above, it may not be possible or safe for fire fighters to always position themselves upwind when using the chain saw to cut trees or brush. Although respirators are not widely used by the wildland fire fighting community as a whole, their use could be considered until wood dust exposures are reduced further.

NIOSH classifies all wood dust as a potential occupational carcinogen. ACGIH classifies wood dust from oak and beech as confirmed human carcinogens; birch, mahogany, teak, and walnut as suspected human carcinogens; and considers all other woods as not classifiable as human carcinogens. The International Agency for the Research on Cancer has also determined that there sufficient evidence that wood dusts are human carcinogens associated with the development of cancers in the nose, paranasal sinuses, and the nasopharynx [International Agency for Research on Cancer 2012]. Because of the cancer risk from exposures to wood dust, efforts should be made to reduce exposures to as low as feasible. In addition, wood dust exposure has been associated with the development of asthma and allergic contact dermatitis [Estlander et al. 2001; Perez-Rios et al. 2010]. Many different tree species have been implicated in both the development of asthma and allergic contact dermatitis among workers exposed to wood dusts. However, individual reaction may differ widely depending on tree species. Our questionnaire revealed 20 fire fighters with a possible asthma-like symptoms, but only five of these respondents had a pre-existing history of asthma. Therefore, it is possible that wood dust overexposure may be contributing to these symptoms. Further pulmonary evaluation is needed on these fire fighters to determine if they show objective evidence of asthma and if so, what exposures may trigger their asthma.

Aside from $\mathrm{CO}$, wildfire smoke contains particulates of 2.5 microns in diameter, polyaromatic hydrocarbons, and levoglucosan, a product of combustion of cellulose. Several studies have shown that these products of wood combustion may decrease lung function in wildland fire fighters across fire seasons [Adetona et al. 2013; Gaughan et al. 2014; Hagberg et al. 1985; Harrison et al. 1995]. The extent to which of these specific factors may impact lung function may vary between individuals. It important that healthcare providers are aware of the multiple factors that may contribute to new onset asthma and/or decreases in lung function in wildland fire fighters. These factors should be included in an assessment of new work-related asthma symptoms. The U.S. Forest Service, the National Park Service, and other U.S. agencies have stood up the Wildland Fire Air Quality Response Program (https:// wildlandfiresmoke.net) that issues air quality alerts using data from incident command, the National Oceanic and Atmospheric Administration, and other partners to create messages for residents of communities surrounding actively burning wildfires and those among the likely smoke distribution area. These alerts can and should be used by fire fighters themselves to be aware of ongoing exposures from the fires that may compromise their respiratory system. Aside from its potential impact on the respiratory system, wildland fire fighters should also be aware that chronic low level $\mathrm{CO}$ exposure may also have deleterious effects on the heart, possibly resulting in chest pain and/or irregular heartbeat [EPA 2016]. 


\section{Noise and Hearing Conservation}

In our evaluation, fire fighters' noise exposures were well above the NIOSH REL and OSHA AL during fuel reduction activities. We found that noise levels and exposures during sawing were slightly higher than during swamping and were also higher when sawing larger diameter trees compared to brush or small diameter trees. Full-shift exposures will vary on the basis of the amount of time spent sawing and cutting larger diameter trees, and may exceed full-shift TWA of $100 \mathrm{dBA}$, depending on the relative ratio of each. Noise exposures that we measured during training exercises near the chipper were at or above $100 \mathrm{dBA}$. We expect that full-shift TWA noise exposure under typical daily use of the chipper would also be similar. At an exposure of $100 \mathrm{dBA}$, the NIOSH REL is exceeded in 15 minutes, and the OSHA AL is exceeded in 60 minutes. NIOSH recommends use of both ear plugs and ear muffs when noise exposures are above $100 \mathrm{dBA}$.

Only one of the 42 fire fighters with completed baseline and annual audiograms showed an OSHAdefined STS, but nine showed a NIOSH-defined significant hearing threshold shift. NIOSH recommends, as good practice, that employees with annual audiograms showing a significant hearing threshold shift be immediately retested to verify the shift and, if verified, re-tested again within 30 days to confirm the shift. Because confirmation testing of audiometric results was not completed, some of these NIOSH threshold shifts may have not persisted. However, these results indicate that audiometric test results should be evaluated using NIOSH criteria, in addition to OSHA criteria, to identify hearing thresholds shifts. The greater sensitivity of the NIOSH criteria provides an opportunity for early intervention to prevent progression of hearing loss.

Our review of audiometric test results for 69 fire fighters showed that $10 \%$ met the ASHA definition for moderate, moderately severe, or severe hearing loss [ASHA 2018]. In contrast, we identified a much higher percentage $(29 \%)$ of the NIOSH questionnaire respondents as having moderate hearing trouble. The higher percentage of self-reported hearing trouble compared to those with hearing loss identified by audiogram may be partially due to subjectivity of self-reported responses compared to audiometric measurements. Rosso et al. [2011] found that the sensitivity of a hearing loss questionnaire in detecting noise-induced hearing loss (NIHL) was $29 \%$.

Prior to baseline and annual audiograms, the audiometric test provider does brief medical and audiometric history pre-screening of each fire fighter. Fourteen (20\%) of the 69 fire fighters subjectively reported during pre-screening of having ringing or roaring in the ears. Ringing or roaring in the ears in the absence of external noise is a common symptom of tinnitus, which can be permanent or temporary in nature. NIOSH research indicates that, among workers reporting exposure to loud noise, the prevalence of tinnitus was 15\% [Masterson et al. 2016]. Research has shown that tinnitus can occur in those with normal hearing [Schaette and McAlpine 2011]. However, tinnitus tends to increase with age and occur more commonly in workers who also have hearing loss. The average age of these 14 fire fighters was 26 years (range: 21-31 years). Only one had ASHA-defined severe hearing loss, and another had moderately severe hearing loss. We did not have information on whether follow-up questions regarding occurrence, persistence, or extent of ringing in the ears were asked. Therefore, it is difficult to interpret the implications of these reported tinnitus symptoms. During future audiometric testing, additional evaluation should be done when fire fighters report tinnitus symptoms. 
The fire fighters' exposures to CO could also potentially affect hearing loss. In laboratory animals, research has shown that CO can worsen NIHL [EU-OSHA 2009]. In addition, the combined exposure to noise and $\mathrm{CO}$ was shown to cause hearing threshold shifts where exposure to either alone did not cause threshold shifts. Analysis of a Quebec National Public Health Institute database of 1,031 workers showed that workers exposed to $\mathrm{CO}$ and noise greater than $90 \mathrm{dBA}$ had worse hearing (particularly at frequencies of 3, 4, and $6 \mathrm{kHz}$ ) than workers exposed to similar noise alone [Johnson and Morata 2009]. The potential risk of hearing loss from combined exposure to noise and $\mathrm{CO}$ highlights the importance of reducing exposures to each and using hearing protection.

\section{Hand-transmitted Vibration}

Prolonged exposure to hand-transmitted vibration is associated with a series of disorders in the vascular, sensorineural and musculoskeletal structures of human fingers-hand-arm system, which has been collectively called HAVS [Gemne and Taylor 1983]. Because blanching along with tingling and numbness in the fingers is a typical symptom of HAVS, VWF is also used to refer the vibration-induced disorders in the fingers and the hand. In our evaluation, $73 \%$ of participating fire fighters reported one or more symptom that could be consistent with HAVS. We also found a significant positive association between reporting HAVS symptoms and use of a leaf blower in the previous 8 weeks. Leaf blower use should also be limited to the lowest possible levels. Routine tool maintenance should include inspection of leaf blower blades and assessment of leaf blower motor operation, as these are the most common sources of increased tool vibration.

We did not find an association between symptoms that could be consistent with HAVS and use of a chain saw in the previous 8 weeks. Nevertheless, vibration exposure has been associated with the development of musculoskeletal disorders among chain saw operators [Bovenzi 2008; Sutinen et al. 2006]. The average frequency-weighted chain saw acceleration measurements in these evaluations $\left(8.4 \mathrm{~m} / \mathrm{s}^{2}\right)$ is at the upper end of the range $\left(5.9-8.8 \mathrm{~m} / \mathrm{s}^{2}\right)$ reported for common chain saws on the European Union market [Griffin et al. 2006]. Career forestry workers with vibration exposures in this range have been reported to show prevalence rates of VWF of up to $50 \%$ [Bovenzi 1995]. In an effort to reduce the vibration exposures to chain saw operators, tool manufacturers have developed anti-vibration (AV) chain saw models. These saws have been reported to exhibit frequency-weighted accelerations in the range of 1.8-2.2 m/ $\mathrm{s}^{2}$ [Sutinen et al. 2006]. However, even operators using these modern, AV chain saw models can still exhibit VWF prevalence rates of more than $10 \%$ after just a few years of forestry work [Bovenzi 2008; Sutinen et al. 2006]. This suggests that there are no completely safe levels of chain saw vibration exposure; chain saw

vibration exposures should be limited to the lowest possible levels.

ANSI has established the ANSI S2.70 standard [ANSI 2006] for the measurement and evaluation of hand-transmitted vibration exposures. This standard prescribes a DEAV of $A(8)=2.5 \mathrm{~m} / \mathrm{s}^{2}$. According to the standard:

The DEAV represents the health risk threshold to hand-transmitted vibration.

For the purpose of this standard, health risk thresholds defined as the dose of 
hand-transmitted vibration exposure sufficient to produce abnormal signs, symptoms, and laboratory findings in the vascular, bone or joint, neurological, or muscular systems of the hands and arms in some exposed individuals.

The standard further states that when the DEAV is exceeded, "a program to reduce worker exposure to hand-transmitted vibration should be initiated to reduce health risks." The ANSI standard [ANSI 2006] has also established a DELV of $A(8)=5.0 \mathrm{~m} / \mathrm{s}^{2}$. Workers exposed to hand-transmitted vibration at or above the DELV "are expected to have a high health risk." The standard recommends that workers not be exposed to vibrations above the DELV. The standard provides guidance for a program to reduce worker exposure to hand-transmitted vibration in Annexes B and C of the standard; guidance applicable to chain saw operators are presented in the recommendations section below.

It is not known if the chain saws used in these evaluations are representative of their respective models. Caution should be used when comparing the vibration emissions of saw models based on such a small sample size. Saw model comparisons based on the results of these limited evaluations may not be appropriate. Likewise, it is not known if the sawing tasks observed in these evaluations are appropriate representations of sawing tasks performed by fire fighters during a typical work shift. Vibration exposures during actual work shifts may be higher or lower than those observed in these evaluations.

It is well known that tool maintenance is a significant factor that can influence the amount of vibration transmitted to the operator. Proper saw maintenance and chain sharpening can help limit hand-transmitted vibration exposure. The saws and chains used during these evaluations were not new, but all units appeared to be well-maintained. However, the ages and hours of use logged on each tool was unknown. It could be that the levels of vibration measured during these evaluations reflected the age and the amount of use that had been logged on each particular saw and/or chain; brand new saws and chains might have yielded different results. However, these saws were randomly selected from the group of saws that are regularly used by these fire fighters. Therefore, the acceleration averages of the four saws evaluated are likely to be fairly typical of what would be observed during similar sawing tasks in the field.

Recent studies suggest that while some AV gloves can significantly reduce vibrations to the palm, AV gloves reduce chain saw vibrations to the fingers by an average of just 4\% [Welcome et al. 2016]. Some glove designs may even amplify chain saw vibrations transmitted to the fingers. Because thicker gloves, such as AV gloves, can increase the grip effort required to operate and maneuver a saw, their use could lead to fatigue or other ergonomic issues [Hewitt et al 2015; Wimer et al. 2010]. Increased grip strength may be a separate contributing risk factor for both carpal tunnel syndrome and HAVS.

\section{Conclusions}

Our evaluation found that fire fighters at this site are overexposed to $\mathrm{CO}$, wood dust, noise, and vibration. Although average $\mathrm{CO}$ concentrations measured on fire fighters were low, peak exposures exceeded relevant OELs. Combined exposure to noise with $\mathrm{CO}$ exposure can worsen the resultant hearing loss, highlighting the importance of reducing exposures to both. Several fire fighters reported symptoms that could be consistent with work-related asthma. 
In total, $73 \%$ of participating fire fighters reported one or more symptoms that could be consistent with HAVS. On the basis of the chain saw vibration measurements during this evaluation, an operator could be expected to reach a hand-transmitted vibration dose at the ANSI S2.70 DEAV in less than two hours of saw operation during a work shift. For some saws, the ANSI DELV could be exceeded in that amount of time. According to the ANSI standard and research on occupational chain saw vibration exposures, prolonged exposures to hand-transmitted vibrations at the levels observed in these evaluations may put the saw operators at risk of developing symptoms of HAVS.

\section{Recommendations}

On the basis of our findings, we recommend the actions listed below. We encourage the fire management facility to use a labor-management health and safety committee or working group to discuss our recommendations and develop an action plan. Those involved in the work can best set priorities and assess the feasibility of our recommendations for the specific situation at this facility.

Our recommendations are based on an approach known as the hierarchy of controls (Appendix A). This approach groups actions by their likely effectiveness in reducing or removing hazards. In most cases, the preferred approach is to eliminate hazardous materials or processes and install engineering controls to reduce exposure or shield fire fighters. Until such controls are in place, or if they are not effective or feasible, administrative measures and personal protective equipment may be needed.

\section{Engineering Controls}

Engineering controls reduce fire fighters' exposures by removing the hazard from the process or by placing a barrier between the hazard and the employee. Engineering controls protect fire fighters effectively without placing primary responsibility of implementation on the employee.

1. Select chain saw models and leaf blowers that are of good ergonomic design, that have been shown to produce reduced hand-transmitted vibration exposures, and that are appropriately sized for the task.

2. Sharpen chains often and maintain the saws in accordance with the manufacturers' specifications. Poorly-maintained saws can generate increased vibrations, noise, CO, and wood dust exposures.

3. Consult the manufacturer of the wood chipper to determine if it can be retrofitted with any noise controls.

\section{Administrative Controls}

The term administrative controls refers to employer-dictated work practices and policies to reduce or prevent hazardous exposures. Their effectiveness depends on employer commitment and employee acceptance. Regular monitoring and reinforcement are necessary to ensure that policies and procedures are followed consistently.

1. When reviewing audiograms to identify hearing threshold shifts, use NIOSH threshold shift criteria in addition to OSHA threshold shift criteria. Also, improve notification 
letter language to increase fire fighter understanding of their test results. The letter should use plain language such as "Your hearing test shows your hearing was normal" or "Your test shows you have mild, moderate, or severe hearing loss."

2. Assess fire fighters reporting tinnitus symptoms to determine occurrence, persistence, and extent of symptoms and whether additional audiology follow-up is needed.

3. Limit the duration of and intensity of hand-transmitted vibration exposure. Design the work and work schedules so that the chain saw operator's daily hand-transmitted vibration exposures remain below the ANSI S2.70 time- and frequency-weighted DELV of $5.0 \mathrm{~m} / \mathrm{s}^{2}$.

4. Employ a rotation schedule that rotates fire fighters between tasks during a work shift and includes extended periods of no vibration exposure. One option is for fire fighters to work in teams of two or more; one operates the saw and the other manages the cuttings, performs saw/chain maintenance, and so on. At prescribed intervals, such as the emptying of a fuel tank, the team members should swap tasks. In this fashion, the vibration exposure is distributed more evenly among the team members during the shift which lessens the chance of overexposure.

5. Avoid awkward sawing postures and unnecessary static loads related to the weight of the saws.

6. Provide adequate training to instruct chain saw operators on the proper use and maintenance of the saws and chains to increase safety and to reduce exposure to handtransmitted vibration.

7. Educate fire fighters about the sources and conditions that may result in $\mathrm{CO}$ and wood dust exposures, with emphasis on actions which may help reduce exposures.

8. Encourage fire fighters to report work-related health symptoms, strains, and pain to their supervisor and promptly seek medical attention from a healthcare provider for those symptoms.

\section{Personal Protective Equipment}

Personal protective equipment is the least effective means for controlling hazardous exposures. Proper use of personal protective equipment requires a comprehensive program and a high level of employee involvement and commitment. The right personal protective equipment must be chosen for each hazard. Supporting programs such as training, changeout schedules, and medical assessment may be needed. Personal protective equipment should not be the sole method for controlling hazardous exposures. Rather, personal protective 
equipment should be used until effective engineering and administrative controls are in place.

1. Require fire fighters to get medically cleared, fit tested for, trained on, and then wear N95 filtering facepiece respirators until wood dust exposures during fuel reduction activities can be reduced. Ensure that fire fighters do not have beard growth that interferes with the sealing surface of respirators.

2. Follow the OSHA respiratory protection standard, 29 CFR 1910.134, for a comprehensive respiratory protection program. Utah follows the federal standard through their state-based program. Information from NIOSH can also help in developing an effective respirator program.

See http://www.cdc.go/niosh/topics/respirators/.

3. Require use of both ear plugs and ear muffs when operating and feeding the chipper.

4. Ensure that fire fighters only use agency provided hearing protection and keep the hearing protection clean or replace disposable earplugs, when necessary.

5. Provide appropriate gloves to protect the hands and to keep them warm and dry. In addition to protection afforded by regular work gloves, AV gloves are designed to reduce hand-transmitted vibration exposures. However, the effectiveness of AV gloves is tool-specific. Therefore, users should contact the glove supplier or manufacturer to determine which glove models are appropriate for use with chainsaws and other equipment. 


\section{Appendix A: Occupational Exposure Limits and Health Effects}

NIOSH investigators refer to mandatory (legally enforceable) and recommended OELs for chemical, physical, and biological agents when evaluating workplace hazards. OELs have been developed by federal agencies and safety and health organizations to prevent adverse health effects from workplace exposures. Generally, OELs suggest levels of exposure that most employees may be exposed to for up to 10 hours per day, 40 hours per week, for a working lifetime, without experiencing adverse health effects. However, not all employees will be protected if their exposures are maintained below these levels. Some may have adverse health effects because of individual susceptibility, a pre-existing medical condition, or a hypersensitivity (allergy). In addition, some hazardous substances act in combination with other exposures, with the general environment, or with medications or personal habits of the employee to produce adverse health effects. Most OELs address airborne exposures, but some substances can be absorbed directly through the skin and mucous membranes.

Most OELs are expressed as a TWA exposure. A TWA refers to the average exposure during a normal 8- to 10-hour workday. Some chemical substances and physical agents have recommended short-term exposure limit or ceiling values. Unless otherwise noted, the shortterm exposure limit is a 15-minute TWA exposure. It should not be exceeded at any time during a workday. The ceiling limit should not be exceeded at any time.

In the United States, OELs have been established by federal agencies, professional organizations, state and local governments, and other entities. Some OELs are legally enforceable limits; others are recommendations.

- The U.S. Department of Labor OSHA PELs (29 CFR 1910 [general industry]; 29 CFR 1926 [construction industry]; and 29 CFR 1917 [maritime industry]) are legal limits. These limits are enforceable in workplaces covered under the Occupational Safety and Health Act of 1970 .

- NIOSH RELs are recommendations based on a critical review of the scientific and technical information and the adequacy of methods to identify and control the hazard. NIOSH RELs are published in the NIOSH Pocket Guide to Chemical Hazards [NIOSH 2010]. NIOSH also recommends risk management practices (e.g., engineering controls, safe work practices, employee education/training, personal protective equipment, and exposure and medical monitoring) to minimize the risk of exposure and adverse health effects.

- Another set of OELs commonly used and cited in the United States is the ACGIH TLVs. The TLVs are developed by committee members of this professional organization from a review of the published, peer-reviewed literature. TLVs are not consensus standards. They are considered voluntary exposure guidelines for use by industrial hygienists and others trained in this discipline "to assist in the control of health hazards" [ACGIH 2019]. 
Outside the United States, OELs have been established by various agencies and organizations and include legal and recommended limits. The Institut für Arbeitsschutz der Deutschen Gesetzlichen Unfallversicherung (Institute for Occupational Safety and Health of the German Social Accident Insurance) maintains a database of international OELs from European Union member states, Canada (Québec), Japan, Switzerland, and the United States. The database, available at http://www.dguv.de/ifa/GESTIS/GESTIS-Internationale-Grenzwerte-für-chemischeSubstanzen-limit-values-for-chemical-agents/index-2.jsp, contains international limits for more than 2,000 hazardous substances and is updated periodically.

OSHA requires an employer to furnish employees a place of employment free from recognized hazards that cause or are likely to cause death or serious physical harm [Occupational Safety and Health Act of 1970 (Public Law 91-596, sec. 5(a)(1))]. This is true in the absence of a specific OEL. It also is important to keep in mind that OELs may not reflect current health-based information.

When multiple OELs exist for a substance or agent, NIOSH investigators generally encourage employers to use the lowest OEL when making risk assessment and risk management decisions. NIOSH investigators also encourage use of the hierarchy of controls approach to eliminate or minimize workplace hazards. This includes, in order of preference, the use of (1) substitution or elimination of the hazardous agent, (2) engineering controls (e.g., local exhaust ventilation, process enclosure, dilution ventilation), (3) administrative controls (e.g., limiting time of exposure, employee training, work practice changes, medical surveillance), and (4) personal protective equipment (e.g., respiratory protection, gloves, eye protection, hearing protection). Control banding, a qualitative risk assessment and risk management tool, is a complementary approach to protecting employee health. Control banding focuses on how broad categories of risk should be managed. Information on control banding is available at http://www.cdc.gov/niosh/topics/ctrlbanding/. This approach can be applied in situations where OELs have not been established or can be used to supplement existing OELs.

\section{Carbon Monoxide}

$\mathrm{CO}$ is a colorless, odorless, tasteless gas produced by incomplete burning of carbon-containing materials; e.g., gasoline. The initial symptoms of CO poisoning may include headache, dizziness, drowsiness, and nausea. These initial symptoms may advance to vomiting, loss of consciousness, and collapse if prolonged or high exposures are encountered. Coma or death may occur if high exposures continue. Exposure to CO limits the ability of the blood to carry oxygen to the tissues by binding with the hemoglobin to form carboxyhemoglobin $(\mathrm{COHb})$ [ACGIH 2001; NIOSH 1972, 1977, 1979, 2010; Proctor et al. 1988].

The NIOSH REL for CO is 35 ppm for an 8-hour TWA exposure, with a ceiling limit of 200 ppm, which should not be exceeded [NIOSH 2010]. The NIOSH REL is designed to protect workers from health effects associated with $\mathrm{COHb}$ levels in excess of 5\% [NIOSH 1972]. The ACGIH recommends a TLV of $25 \mathrm{ppm}$ as an 8-hour TWA, and this is designed to protect workers from health effects associated with $\mathrm{COHb}$ levels in excess of 3.5\% [ACGIH 2001]. The OSHA PEL for CO is 50 ppm for an 8-hour TWA exposure (29 CFR 1910.1000). 


\section{Wood Dust}

Wood dust exposure may cause eye and skin irritation and respiratory effects. In industrial settings, certain hard woods, such as oak, maple, and walnut, have been linked to nasal cancer [Proctor et al. 1991]. Loggers and persons involved in initial wood processing are exposed to irritant chemicals found in the bark or sap in the outer part of the tree. They are most affected by primary irritant dermatitis, which consists of erythema and blistering [Proctor et al. 1991]. The adverse health effects that have been associated with exposure to wood dust upon which evaluation criteria are based include dermatitis, allergic respiratory effects, and mucosal and nonallergenic respiratory effects.

NIOSH recommends that wood dust be considered a potential occupational carcinogen and that exposures be reduced to the lowest feasible level, not to exceed the REL of $1 \mathrm{mg} / \mathrm{m}^{3}$ for both soft and hard woods [NIOSH 2010]. ACGIH has a TLV of $0.5 \mathrm{mg} / \mathrm{m}^{3}$ for Western Red Cedar and $1 \mathrm{mg} / \mathrm{m}^{3}$ for all other species [ACGIH 2018]. There is currently no specific OSHA PEL for wood dust. The OSHA PEL for total particulate not otherwise regulated is $15.0 \mathrm{mg} / \mathrm{m}^{3}$ and $5.0 \mathrm{mg} / \mathrm{m}^{3}$ for the respirable fraction, determined as 8-hour averages (29 CFR 1910.1000).

\section{Noise}

NIHL is an irreversible condition that progresses with noise exposure. It is caused by damage to the nerve cells of the inner ear and, unlike some other types of hearing disorders, cannot be treated medically [Berger et al. 2003]. More than 22 million U.S. workers are estimated to be exposed to workplace noise levels above $85 \mathrm{dBA}$ [Tak et al. 2009]. NIOSH estimates that workers exposed to an average daily noise level of $85 \mathrm{dBA}$ over a 40 -year working lifetime have an $8 \%$ excess risk of material hearing impairment. This excess risk increases to $25 \%$ for an average daily noise exposure of $90 \mathrm{dBA}$ [NIOSH 1998]. NIOSH defines material hearing impairment as an average of the hearing threshold levels for both ears that exceeds 25-decibel (dB) at frequencies of $1000 \mathrm{~Hz}, 2000 \mathrm{~Hz}, 3000 \mathrm{~Hz}$, and $4000 \mathrm{~Hz}$.

Although hearing ability commonly declines with age, exposure to excessive noise can increase the rate of hearing loss. In most cases, NIHL develops slowly from repeated exposure to noise over time, but the progression of hearing loss is typically the greatest during the first several years of noise exposure. NIHL can also result from short duration exposures to high noise levels or even from a single exposure to an impulse noise or a continuous noise, depending on the intensity of the noise and the individual's susceptibility to NIHL [Berger et al. 2003]. Noise exposed workers can develop substantial NIHL before it is clearly recognized. Even mild hearing losses can impair one's ability to understand speech and hear many important sounds. In addition, some people with NIHL also develop "tinnitus." Tinnitus is a condition in which a person perceives hearing sound in one or both ears, but no external sound is present. Persons with tinnitus often describe hearing ringing, hissing, buzzing, whistling, clicking, or chirping like crickets. Tinnitus can be intermittent or continuous and the perceived volume can range from soft to loud. Currently, no cure for tinnitus exists.

The preferred unit for reporting noise measurements is dBA. A-weighting is used because it approximates the "equal loudness perception characteristics of human hearing for pure tones 
relative to a reference of $40 \mathrm{~dB}$ at a frequency of $1,000 \mathrm{~Hz}$ " and is considered to provide a better estimation of hearing loss risk than using unweighted or other weighting measurements [Berger et al. 2003]. NIOSH has an REL for noise of $85 \mathrm{dBA}$, as an 8-hour TWA. The OSHA noise standard specifies a PEL of $90 \mathrm{dBA}$ and an AL of $85 \mathrm{dBA}$, both as 8-hour TWAs. Exposure to impulsive noise should never exceed $140 \mathrm{dBA}$.

For noise exposure measurements, NIOSH uses an $80 \mathrm{dBA}$ threshold and a $3-\mathrm{dB}$ exchange rate. Noise below the threshold level is not integrated by the noise dosimeter during measurements. The exchange rate expresses how much the sound level could increase or decrease while keeping the risk of hearing loss the same, if the exposure duration was simultaneously decreased or increased. For example, a 3-dB exchange rate requires that noise exposure time be halved for each $3-\mathrm{dB}$ increase in noise levels. NIOSH considers noise measured using the $3-\mathrm{dB}$ exchange rate to more accurately relate noise exposures to hearing loss risk [NIOSH 1998]. Using this criterion, an employee can be exposed to $88 \mathrm{dBA}$ for no more than 4 hours, $91 \mathrm{dBA}$ for 2 hours, $94 \mathrm{dBA}$ for 1 hour, $97 \mathrm{dBA}$ for 0.5 hours, etc. For extended work shifts, NIOSH adjusts the REL to $84.5 \mathrm{dBA}$ for a 9-hour shift, $84.0 \mathrm{dBA}$ for a 10-hour shift, 83.6 dBA for an 11-hour shift, and 83.2 dBA for a 12-hour work shift. When noise exposures exceed the REL, NIOSH recommends the use of hearing protection and implementation of a hearing loss prevention program [NIOSH 1998].

OSHA uses a $90 \mathrm{dBA}$ threshold and a 5-dB exchange rate for the PEL measurements and an $80 \mathrm{dBA}$ threshold and 5-dB exchange rate for the AL measurements. Using the OSHA criterion, an employee may be exposed to noise levels of $95 \mathrm{dBA}$ for no more than 4 hours, $100 \mathrm{dBA}$ for 2 hours, $105 \mathrm{dBA}$ for 1 hour, $110 \mathrm{dBA}$ for 0.5 hours, etc. OSHA does not adjust the PEL for extended work shifts. However, the AL is adjusted to $84.1 \mathrm{dBA}$ for a 9-hour shift, 83.4 dBA for a 10-hour shift, $82.7 \mathrm{dBA}$ for an 11-hour shift, and 82.1 dBA for a 12-hour work shift. OSHA requires implementation of a hearing conservation program when noise exposures exceed the AL [29 CFR 1910.95].

Workers exposed to noise should have baseline and yearly hearing tests to evaluate their hearing thresholds and determine whether their hearing has changed over time. Hearing testing should be done in a quiet location, such as an audiometric test booth where background noise does not interfere with accurate measurement of hearing thresholds. In workplace hearing conservation programs, hearing thresholds must be measured at $500 \mathrm{~Hz}$, $1000 \mathrm{~Hz}, 2000 \mathrm{~Hz}, 3000 \mathrm{~Hz}, 4000 \mathrm{~Hz}$, and $6000 \mathrm{~Hz}$. Additionally, NIOSH recommends that $8000 \mathrm{~Hz}$ should also be tested [NIOSH 1998]. The OSHA hearing conservation standard requires analysis of changes from baseline hearing thresholds to determine if the changes are substantial enough to meet OSHA criteria for a STS. OSHA defines a STS as a change in hearing threshold relative to the baseline hearing test of an average of $10 \mathrm{~dB}$ or more at 2000 $\mathrm{Hz}, 3000 \mathrm{~Hz}$, and $4000 \mathrm{~Hz}$ in either ear [29 CFR 1910.95]. If a STS occurs, the company must determine if the hearing loss also meets the requirements to be recorded on the OSHA Form 300 Log of Work-Related Injuries and Illnesses [29 CFR 1904.1]. In contrast to OSHA, NIOSH defines a significant threshold shift as an increase in the hearing threshold level of $15 \mathrm{~dB}$ or more, relative to the baseline audiogram, at any test frequency in either ear measured twice in succession [NIOSH 1998]. 


\section{Vibration}

Prolonged exposure to hand-transmitted vibration is associated with a series of disorders in the vascular, sensorineural and musculoskeletal structures of human fingers-hand-arm system, which has been collectively called HAVS [Gemne and Taylor 1983]. Vibration exposure has been associated with the development of musculoskeletal disorders among chain saw operators [Bovenzi 2008; Sutinen et al. 2006].

Tri-axial vibration data were collected via a portable six-channel B\&K PULSE system (Brüel \& Kjær, Input/Output Module Type 3032A). The vibration data collected from this system were expressed as the root-mean-square ( $\mathrm{rms}$ ) values of the accelerations in the one-third octave frequency bands, with center frequencies from 6.3 to 1,250 Hz. The sampling rate of the B\&K system is 2.56 times the highest frequency sampled, or in this case, 3,200 Hz. Both time-history data and frequency spectrum were recorded. The vector sum, or 'total' values of the unweighted rms accelerations were computed using the following formula:

$$
a_{h}=\sqrt{a_{h x}^{2}+a_{h y}^{2}+a_{h z}^{2}}
$$

where $a_{h}$ is the unweighted root-sum-of-squares total value, and $a_{h x}, a_{h y}$, and $a_{h z}$, are the unweighted rms acceleration values for the $\mathrm{x}-, \mathrm{y}-$, and $\mathrm{z}$-axis, respectively.

To determine the ISO frequency-weighted acceleration values for each axis, an Excel spreadsheet was used to apply the frequency-weighting factors defined in ISO 5349-1 [ISO 2001a]:

$$
a_{h w}=\sqrt{\sum_{j=1}^{24}\left(w_{j} a_{h, j}\right)^{2}}
$$

where $a_{h w}$ is the single-axis frequency-weighted rms acceleration, $w_{j}$ is the weighting factor for the jth one-third octave band as provided in Table 2 of the standard, and $a_{h, \mathrm{j}}$ is the acceleration measured in the jth one-third octave band. In this process, the 24 one-third octave frequency band rms accelerations are multiplied by their respective weighting factors, and the resultant weighted rms accelerations are determined for each axis.

Next, as is done with the unweighted acceleration, the total ISO frequency-weighted values are computed using

$$
a_{h v}=\sqrt{a_{h w x}^{2}+a_{h w y}^{2}+a_{h w z}^{2}}
$$

where $a_{h v}$ is the ISO frequency-weighted root-sum-of-squares total value, and $a_{h w x}, a_{h w y}$, and $a_{h w z}$ are the ISO frequency-weighted rms acceleration values for the $\mathrm{x}-, \mathrm{y}-$, and $\mathrm{z}$-axis, respectively.

Using the above-described acceleration measurements, the ISO frequency-weighted saw handle vibration measurements $\left(a_{h v}\right)$ can be used to estimate hand-transmitted vibration 
exposures associated with the sawing tasks and saws evaluated in these evaluations. Estimated frequency- and time-weighted daily vibration exposure values, $\mathrm{A}(8)$, can be calculated using the methods outlined in ANSI S2.70-2006 [ANSI 2006]. The standard equation for estimating $A(8)$ values is

$$
A(8)=a_{h v} \sqrt{\frac{T}{T_{0}}}
$$

where $A(8)$ is the daily vibration exposure in $\mathrm{m} / \mathrm{s}^{2}$, ahv is the total ISO frequency-weighted vibration magnitude (see Equation 3 above), $T$ is the total daily duration of the exposure (in hours), and $T_{0}$ is the reference duration of eight hours. Once the $\mathrm{A}(8)$ values are determined, those values can be compared with the DEAV of $A(8)=2.5 \mathrm{~m} / \mathrm{s}^{2}$ and the DELV of $A(8)=5.0 \mathrm{~m} / \mathrm{s}^{2}$ established in the ANSI standard [ANSI 2006]. 


\title{
Appendix B: Interim Report on Safety Climate, Job Stress, Psychosocial Factors at Work, and Sleep
}

May 2, 2016

HHE 2015-0028

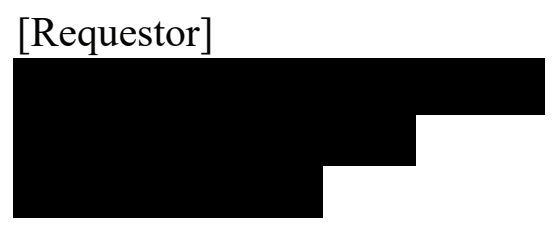

Dear [Requestor]:

This interim report is in response to the National Institute for Occupational Safety and Health (NIOSH) health hazard evaluation (HHE) you requested in December 2014 for wildland firefighter employees of The request concerned potential exposures to hand-arm vibration, wood chipper dust, noise; safety climate; and job stress among employees. This interim report focuses on safety climate and job stress.

\begin{abstract}
hires more than 100 state employees and college interns from the Utah Valley University's Fire and Rescue Academy. Their mission is to suppress wildland fires, reduce hazards to communities at risk of fire, and improve forest health. All crews complete natural resource and fire management projects when not engaged in fire suppression. While completing projects, crews usually set up remote field camps for up to 8 days at a time and are subject to primitive living conditions. The crews take their firefighting equipment to these camps and are on call for fire assignments as they arise [ـ 2015].
\end{abstract}

\section{Methods}

We visited headquarters at the beginning of the fire season in May 2015 and again at the end of the season in October 2015 to conduct confidential interviews with employees. At the beginning of the season, most employees were engaged in training activities, administrative tasks, and preparing for the season. When we visited at the end of the season, the employees were engaged in season closeout procedures, making sure equipment was accounted for, and other administrative tasks.

During our visits, NIOSH investigators held confidential interviews with employees at the headquarters, with the exception of one crew (Hotshots). We interviewed the
Hotshots crew in vehicles while they were completing field work during our visit at the
beginning of the fire season in May 2015. The interviews took approximately 10 minutes to
complete, and included scaled and open-ended questions.

\section{$\underline{\text { Safety Climate }}$}

The interview included a six-item measure of safety climate [Hahn and Murphy 2008], which included questions about the following: management commitment to safety, safety feedback, 
worker involvement in safety, and coworker behavioral norms. The items were read to employees, who were presented with a four-point scale and asked to indicate their level of agreement ( 1 = strongly disagree, $2=$ disagree, 3 =agree, $4=$ strongly agree $)$. One method for scoring these items is to total the scores (possible range 6-24) [NIOSH 2010]. The total is interpreted as:

- Between 6 and 15 indicates a poor safety climate at work

- Between 16 and 20 indicates a fair safety climate at work

- Between 21 and 24 indicates a good safety climate at work

We also analyzed responses by calculating the percentage of employees who indicated agreement with the statements presented to them.

\section{Psychosocial Factors at Work}

The interview also included questions about the following work factors: job demands, decision latitude, perceptions of coworkers, role expectations, job security, training, and work-life conflict. We also asked about job satisfaction and burnout. These items were selected from validated measures of job stressors deemed appropriate for HHEs [Wiegand et al. 2012]. These items were read to employees, who were presented with a four-point scale and asked to indicate their level of agreement $(1=$ strongly disagree, $2=$ disagree, $3=$ agree, $4=$ strongly agree).

\section{$\underline{\text { Job Stress }}$}

We asked employees to rate their level of job stress with the following survey item: "During the past week, including today, how would you rate your current job stress level on a scale from 0 (as low as it can be) to 10 (as high as it can be)?" Responses of 0-3 indicated low job stress, 4-6 indicated moderate job stress, and scores of 7 or greater indicated high job stress [Clark et al. 2011]. This question was followed by an open-ended question asking employees to describe the major sources of stress on their job.

\section{Sleep and Fatigue}

We asked employees about their average sleep duration, quality of sleep, and frequency of unintentional sleep (e.g., dozing off while driving a vehicle).

\section{Results and Discussion}

At the beginning of the season, we interviewed 56 firefighters (96\% male) with an average age of 26 years (range: 19-50 years). This included 21 (38\%) firefighters from the Hotshots, 19 (34\%) from $\quad$ Crew, and 16 (29\%) from $\quad$ Crew. $\longrightarrow$ has other crews that were not present for interviews. Forty-three $(77 \%)$ were seasonal firefighters. Fourteen (25\%) were rookies, $26(46 \%)$ had 2-4 years of experience, and $16(29 \%)$ had $>5$ years of experience working for

At the end of the season, we interviewed 48 firefighters ( $96 \%$ male) with an average age of 27 years (range: 19-36 years). This included 18 (38\%) firefighters from the Hotshots, $11(23 \%)$ from $\quad$ Crew, and 19 (40\%) from $\quad$ Crew. Again, other 
crews were not present at the time of our visit. Thirty-five $(73 \%)$ were seasonal firefighters. Twelve (25\%) were rookies, $18(38 \%)$ had $2-4$ years of experience, and $18(38 \%)$ had $>5$ years of experience working for

We interviewed 36 employees both at the beginning and end of the season. Others were interviewed either at the beginning or the end of the season. When restricting analyses to the 36 employees who were interviewed twice, we found that the results were similar to those found when analyzing the total number of employee responses at the beginning and end of the season. Therefore, we are presenting the results for all participants, whether they participated one or both times.

\section{$\underline{\text { Safety Climate }}$}

In terms of overall safety climate, at the beginning of the season, $12(21 \%)$ of employees reported a fair safety culture at work, while $44(79 \%)$ reported a "good" safety culture at work. At the end of the season, $10(21 \%)$ of employees reported a fair safety culture at work, while $38(79 \%)$ reported a "good" safety culture at work. The number of employees responding either "agree" or "strongly agree" with individual safety climate item are included in Table 1.

Table 1. Employees indicating "agree" or "strongly agree" with individual safety climate items at the beginning and end of the fire season

\begin{tabular}{lcc}
\hline Items & $\begin{array}{c}\text { Beginning of Season } \\
\text { Agreement } \\
\text { Frequency }(\%) \\
\mathrm{N}=56\end{array}$ & $\begin{array}{c}\text { End of Season } \\
\text { Agreement } \\
\text { Frequency (\%) } \\
\mathrm{N}=48\end{array}$ \\
\hline $\begin{array}{l}\text { The health and safety of workers is a high } \\
\text { priority with management where I work. } \\
\text { Workers and management work together to } \\
\text { ensure the safest possible conditions. }\end{array}$ & $56(100)$ & $47(98)$ \\
$\begin{array}{l}\text { New employees learn quickly that they are } \\
\text { expected to follow good health and safety } \\
\text { practices. }\end{array}$ & $55(98)$ & $47(98)$ \\
$\begin{array}{l}\text { Employees are told when they do not follow } \\
\text { good health and safety practices. }\end{array}$ & $55(98)$ & $48(100)$ \\
I feel free to report safety problems where \\
I work.
\end{tabular}

Although the safety climate scores were similarly positive at the beginning and end of the season, two items had slightly less support at the end of the season: "employees are told when they do not follow good health and safety practices" and "there are no major shortcuts taken when worker health and safety are at stake." A possible explanation for these slightly lower levels of agreement is that at the beginning of the season, the employees had just 
completed training where feedback regarding unsafe behaviors (including taking safety shortcuts) may have occurred more often. The experience of live firefighting presents a more chaotic environment where opportunities for employee observation and feedback may not be as common as when in training. Crews may have different supervisors when training than when in the field, so differences in supervisory styles may also have an impact on the employees' perceptions of safety climate at different times of the season.

\section{$\underline{\text { Psychosocial Factors at Work }}$}

The number of employees responding either "agree" or "strongly agree" with the psychosocial items are included in Table 2.

Table 2. Employees indicating "agree" or "strongly agree" with psychosocial items at the beginning and end of the fire season

\begin{tabular}{|c|c|c|}
\hline Items & $\begin{array}{c}\text { Beginning of Season } \\
\text { Agreement } \\
\text { Frequency }(\%) \\
N=56\end{array}$ & $\begin{array}{l}\text { End of Season } \\
\text { Agreement } \\
\text { Frequency (\%) } \\
\qquad \mathrm{N}=48\end{array}$ \\
\hline My job requires working very fast. & $49(88)$ & $47(98)$ \\
\hline I have enough time to get the job done. & $51(91)$ & $37(77)$ \\
\hline $\begin{array}{l}\text { I am free from conflicting demands that } \\
\text { others make while I work. }\end{array}$ & $48(86)$ & $33(69)$ \\
\hline $\begin{array}{l}\text { My job requires long periods of intense } \\
\text { concentration on the task. }\end{array}$ & $56(100)$ & $47(98)$ \\
\hline $\begin{array}{l}\text { I am often required to work for long periods } \\
\text { with my body in physically awkward positions. }\end{array}$ & $47(84)$ & $46(96)$ \\
\hline $\begin{array}{l}\text { I have a lot of say about what happens on } \\
\text { my job. }\end{array}$ & $41(73)$ & $26(54)$ \\
\hline $\begin{array}{l}\text { My job allows me to make a lot of decisions } \\
\text { on my own. }\end{array}$ & $39(70)$ & $34(71)$ \\
\hline $\begin{array}{l}\text { People I work with are helpful in getting the } \\
\text { job done. }\end{array}$ & $56(100)$ & $47(98)$ \\
\hline $\begin{array}{l}\text { It is clear to me what is considered accept- } \\
\text { able performance by my supervisor. }\end{array}$ & $56(100)$ & $47(98)$ \\
\hline $\begin{array}{l}\text { The demands of my job interfere with my } \\
\text { home and family life. }\end{array}$ & $30(54)$ & $40(83)$ \\
\hline $\begin{array}{l}\text { The job training I received adequately } \\
\text { prepared me to do the job correctly and safely. }\end{array}$ & $56(100)$ & $46(96)$ \\
\hline My job security is good. & $50(89)$ & $40(83)$ \\
\hline I feel burned out at work. & $18(32)$ & $32(67)$ \\
\hline Overall, I am satisfied with my job. & $56(100)$ & $42(88)$ \\
\hline $\begin{array}{l}\text { If I were injured or feeling pain (as a result } \\
\text { of my job or otherwise), I would seek } \\
\text { medical attention. }\end{array}$ & N/A & $40(83)$ \\
\hline
\end{tabular}


Employees' responses to the psychosocial items describe their work as physically and mentally demanding, with limited control or "say" about what happens on their jobs. Job stress is thought to increase when employees are faced with high job demands and low decision latitude or job control [Karasek and Theorell 1990].

At the end of the season, nearly one-third of employees reported that they are given conflicting demands from others at work, which may indicate that supervisors and/or employees are not consistently in agreement with job tasks, procedures, or priorities. This warrants further exploration since nearly all employees reported that they know what their supervisor expects of them, both at the beginning and end of the season.

At the end of the fire season, most employees reported that their work interferes with their home and family life. This was to be expected given the employees' lengthy deployments when suppressing fires in remote locations. Work-life conflict may be greater in situations where communication is limited while employees are deployed. Scheduling and poor internet or cell phone connectivity while in remote locations may disrupt communication with individuals and their families, or impede other aspects of life such as paying bills, managing finances, or being informed about current events.

Two-thirds of the employees interviewed at the end of the season reported that they feel burned out at work, compared to one-third at the beginning of the season. This difference can be expected given the timing of the interviews, which is discussed further below. At the end of the season, the firefighters have experienced cumulative strain in their jobs, having been active for five months. Burnout showed a significant negative correlation with job satisfaction $(\mathrm{r}=-0.41, \mathrm{p}<0.01)$, meaning that as burnout increased, job satisfaction decreased.

Some employees reported that they do not have good job security, and this was reported more at the end of the season. Job insecurity is associated with high psychological stress, poor self-rated health [Ferrie et al. 2002], and negative job and organizational attitudes [Sverke et al. 2002].

Most (83\%) employees reported that they would seek medical attention if they were injured or feeling pain as a result of their job. Some of those employees who indicated they would not seek medical attention in these circumstances reported that they would let the injury/pain heal naturally, while others expressed concerns that they would lose job security if they were to seek medical care and miss time at work. Maintaining top physical shape and strength are integral to firefighting work, so it is important that employees seek medical attention for any conditions (e.g., musculoskeletal) which may become chronic or worsen over time, thus putting them at risk for being ineligible for future firefighting work.

\section{$\underline{\text { Job Stress }}$}

Employees were asked to rate their level of job stress on a scale from 0 (as low as it can be) to 10 (as high as it can be). The average job stress score was $3.9(\mathrm{~N}=56)$ at the beginning of the season, indicating moderate job stress overall. On the basis of individual stress scores, 26 (46\%) employees indicated low job stress, 21 (38\%) indicated moderate job stress, and $9(16 \%)$ indicated high job stress. 
Employees were asked an open-ended question to describe the major sources of stress in their jobs. Employees could report multiple stressors, and Table 3 shows job stressors that were reported by 5 or more individuals.

Table 3. Frequency of reported job stressors at the beginning of the fire season $(\mathrm{N}=56)$

\begin{tabular}{lc}
\hline Job stressor & Frequency (\%) \\
\hline Job demands & $19(33)$ \\
Meeting management expectations & $19(33)$ \\
Beginning of season (learning curve, & $18(32)$ \\
getting into a routine) & \\
Responsibility for others & $14(25)$ \\
Safety concerns & $13(23)$ \\
Work-life conflict & $7(12)$ \\
Fatigue & $6(11)$ \\
\hline
\end{tabular}

The most frequently reported stressors were associated with the physically and mentally demanding nature of the job and a desire to perform well to meet management expectations. One-third of employees specifically mentioned that the beginning of the season is a stressful time because they have a steep learning curve with policies and procedures, and they have to ready themselves for the season by developing a disciplined routine of exercise, nutrition, and hard work.

The average job stress score was $5.4(\mathrm{~N}=48)$ at the end of the season, again indicating moderate, yet elevated, job stress overall. On the basis of individual stress scores, $8(17 \%)$ employees indicated low job stress, 24 (50\%) indicated moderate job stress, and $16(33 \%)$ indicated high job stress.

Table 4 shows the job stressors reported by 5 or more individuals when asked an open-ended question.

Table 4. Frequency of reported job stressors at the end of the fire season $(\mathrm{N}=48)$

\begin{tabular}{lc}
\hline Job stressor & Frequency (\%) \\
\hline Job demands & $13(27)$ \\
Work-life conflict & $13(27)$ \\
Responsibility for others & $8(16)$ \\
Time pressure & $7(14)$ \\
Meeting management expectations & $5(10)$ \\
Safety concerns & $5(10)$ \\
Fatigue & $5(10)$ \\
\hline
\end{tabular}


At the end of the season, the most frequently reported stressors were the physically and mentally demanding nature of the job, and work-life conflict from being away from home for long periods over the season.

Firefighting (which may include structural and wildland firefighting) was ranked as the most stressful job in the United States based on an annual study which uses criteria such as deadlines, travel, growth potential, compensation, competitiveness, physical demands, hazards, environmental conditions, and risk to one's life or to others' [CareerCast 2015]. Wildland firefighting presents complex and multifaceted stressors including unpredictability of fires, time pressure, working in remote locations, heightened vigilance, fear of imminent death of self and others, responsibility for others, and exposure to smoke, equipment fumes, noise, hand-arm vibration, and heat, among others.

\section{Sleep and Fatigue}

At the beginning of the season, employees reported getting an average of 7 hours (range: 3-10 hours) of sleep in a 24-hour period. They reported unintentionally falling asleep at least once a day an average of 2 days (range: 0-26 days) per month. Two employees indicated that they had fallen asleep while driving a vehicle in the past month. Employees reported that they felt they did not get adequate rest an average of 6 days (range: 0-30 days) in the last month. Most employees (91\%) indicated that their quality of sleep over the past month was fairly or very good.

At the end of the season, employees reported getting an average of 7 hours (range: 4-8 hours) of sleep in a 24-hour period. They reported unintentionally falling asleep at least once a day an average of 6 days (range: 0-30 days) per month. Five employees indicated that they had fallen asleep while driving a vehicle in the past month. Employees reported that they felt they did not get adequate rest an average of 10 days (range: 0-30 days) in the last month. Most employees $(81 \%)$ indicated that their quality of sleep over the past month was fairly or very good.

Job stress is associated with fatigue. For example, Kashani et al. [2012] found that individuals experiencing high stress had more daytime sleepiness, greater fatigue, poorer sleep quality, and shorter sleep duration than those who experienced low stress. Fatigue can also impair job performance [Dawson and Reid 1997]. Firefighting is an inherently risky profession. It is important that firefighters are vigilant, clear headed, and able to react quickly if in a potentially dangerous situation. Coping with stress and remaining well rested are essential to maintaining well-being and high performance on the job.

Lourel et al. [2008] described research on three important stress-related phases of firefighting. The pre-operational phase occurs during training and when firefighters are anticipating response to a fire. During this time, firefighters tend to experience anxiety and are taxed with increased concentration on tasks. The operational phase is the time when firefighters are taking action at the scene of a fire. During this phase, firefighters experience increased physical and psychological distress. Finally, the post-operational phase occurs when a fire mission is complete and firefighters return to their normal surroundings. During this "decompression" phase, the stress of firefighting begins to manifest in physical soreness, fatigue, and self-reflection or self-criticism. This HHE focused on the pre- and post- 
operational phases of firefighting, so increased job stress and fatigue at the end of the season are to be expected.

\section{Conclusion}

Overall, wildland firefighter employees reported a strong safety climate, favorable perceptions of various psychosocial factors at work, and moderate job stress. Employees reported decreased sleep quality at the end of the season. We present recommendations below to address areas that may need further exploration or improvement on the basis of our interview results.

\section{Recommendations}

1. Talk to employees about job demands and how they affect job stress, burnout, and job satisfaction. Their input may provide insight on how to better cope with high demands and improve perceptions of work.

2. Identify and address potential source(s) of conflicting work demands that some employees report.

3. Talk to employees about why some believe they have poor job security. If the reasons are unfounded, address them with all employees. management should express appreciation and value for employees throughout the season and when applicable, offer reassurance regarding job security in end-of-season performance reviews.

4. Designate someone at headquarters to serve as a liaison between deployed employees and their families in case communication is limited and employees are having difficulty reaching family members or conducting other affairs.

5. Train employees in stress reduction exercises such as controlled breathing, mindfulness, and meditation, and encourage them to practice these techniques during deployment downtime.

6. Encourage employees to report work-related health symptoms, strains, and pain to their supervisor and promptly seek medical attention from a healthcare provider if these symptoms are causing distress.

7. Ensure employees receive adequate training on the importance of good sleep habits, the hazards associated with fatigue at work, and strategies for managing them. For more information on sleep, see http://www.cdc.gov/sleep. 
Thank you for your cooperation with this ongoing evaluation. For the purpose of informing affected employees, we recommend that copies of this letter be posted by the employer in a place accessible to the employees. We are planning another site visit in the spring of 2016 to assess exposure to wood chipper dust, carbon monoxide, noise, and hand/arm vibration, and to complete confidential medical interviews. We will be contacting you to discuss the details of this site visit. After we have performed this follow up evaluation, we will prepare a formal report combining the results and recommendations for all aspects of this health hazard evaluation. If you have any questions, please do not hesitate to contact me at (513) 841-4240 ordwiegand@cdc.gov.

\author{
Sincerely, \\ Douglas Wiegand, PhD \\ Behavioral Scientist \\ Hazard Evaluations and Technical \\ Assistance Branch \\ Division of Surveillance, Hazard \\ Evaluations and Field Studies
}

cc: [Employee Representative]

\title{
References
}

CareerCast [2015]. The most stressful jobs of 2015.

[http://www.careercast.com/jobs-rated/most-stressful-jobs-2015]. Date accessed: April 2016.

Clark MM, Warren BA, Hagen PT, Johnson BD, Jenkins SM, Werneburg BL, Olsen KD [2011]. Stress level, health behaviors, and quality of life in employees joining a wellness center. Am J Health Promot 26(1):21-25.

Dawson D, Reid K [1997]. Fatigue, alcohol and performance impairment. Nature 388:235.

Ferrie JE, Shipley MJ, Stansfeld SA, Marmot MG [2002]. Effects of chronic job insecurity and change in job security on self-reported health, minor psychiatric morbidity, physiological measures and health-related behaviors in British civil servants: the Whitehall II study. J Epidemiol Community Health 56(6):450-454.

Hahn SE, Murphy LR [2008]. A short scale for measuring safety climate. Safety Science 46(7):1047-1066.

Karasek R, Theorell T [1990]. Healthy work: stress, productivity, and the reconstruction of working life. New York, NY: Basic Books.

Kashani M, Eliasson A, Vernalis M [2012]. Perceived stress correlates with disturbed sleep: a link connecting stress and cardiovascular disease. Stress 15(1):45-51. 
Lourel M, Abdellaoui S, Chevaleyre S, Paltrier M, Gana K [2008]. Relationships between psychological job demands, job control and burnout among firefighters. N Am J Psyc 10(3):489-496.

NIOSH [2010]. Stop sticks campaign: safety culture evaluation survey.

[http://www.cdc.gov/niosh/stopsticks/survey.html]. Date accessed: April 2016.

Sverke M, Hellgren J, Näswall, K [2002]. No security: a meta-analysis and review of job insecurity and its consequences. J Occup Health Psych 73(3):242-264.

Wiegand DM, Chen PY, Hurrell JJ Jr., Jex S, Nakata A, Nigam J, Robertson M, Tetrick L [2012]. A consensus method for updating psychosocial measures used in NIOSH health hazard evaluations. J Occup Environ Med 54(3):350-355. 


\section{References}

ACGIH [2019]. 2018 TLVs ${ }^{\circledR}$ and BEIs ${ }^{\circledR}:$ threshold limit values for chemical substances and physical agents and biological exposure indices. Cincinnati, OH: American Conference of Governmental Industrial Hygienists.

ACGIH [2001]. Documentation of threshold limit values and biological exposure indices. 7th ed. Cincinnati, OH: American Conference of Governmental Industrial Hygienists.

Adetona O, Simpson CD, Onstad G, Naeher LP [2013]. Exposure of wildland fire fighters to carbon monoxide, fine particles, and levoglucosan. Ann Occup Hyg 57(8):979-991, https://doi.org/10.1080/15459624.2014.895372.

American Speech-Language-Hearing Association (ASHA) [2018]. Degree of hearing loss. https://www.asha.org/public/hearing/Degree-of-Hearing-Loss/.

ANSI [2006]. ANSI S2.70: guide for the measurement and evaluation of human exposure to vibration transmitted to the hand (Revision of ANSI S3.34-1986). Washington D.C.: American National Standards Institute.

Berger EH, Royster LH, Royster JD, Driscoll DP, Layne M, eds. [2003]. The noise manual. 5th rev. ed. Fairfax, VA: American Industrial Hygiene Association.

Bovenzi M [2008]. A follow up study of vascular disorders in vibration-exposed forestry workers. Int Arch Occup Environ Health 81(4):401-408, https://doi.org/10.1007/s00420-007-0225-9.

Bovenzi M, Franzinelli A, Mancini R, Cannava MG, Maiorano M, Ceccarelli F [1995]. Dose-response relation for vascular disorders induced by vibration in the fingers of forestry workers. Occup Environ Med 52(11):722-730, http://dx.doi.org/10.1136/oem.52.11.722.

CFR. Code of Federal Regulations. Washington, DC: U.S. Government Printing Office, Office of the Federal Register.

EPA, US Forest Service, CDC, and California Air Resources Board [2016]. Wildfire smoke: a guide for public health officials. https://www3.epa.gov/airnow/wildfire may2016.pdf.

Estlander T, Jolanki R, Alanko K, Kanerva L [2001]. Occupational allergic contact dermatitis caused by wood dusts. Contact Dermatitis 44(4):213-217, https://doi.org/10.1034/j.1600-0536.2001.044004213.x.

EU-OSHA [2009]. Combined exposure to noise and ototoxic substances. Bilboa, Spain: European Agency for Safety and Health at Work.

Gaughan DM, Piacitelli CA, Chen BT, Law BF, Virji MA, Edwards NT, Enright PL, Schwegler-Berry DE, Leonard SS, Wagner GR, Kobzik L, Kales SN, Hughes MD, Christiani DC, Siegel PD, Cox-Ganser JM, Hoover MD [2014]. Exposures and cross-shift lung function declines in wildland fire fighters. J Occup Environ Hyg 11(9):591-603, https://doi.org/10.1080/15459624.2014.895372. 
Gemne G, Taylor W [1983]. Foreword: hand-arm vibration and the central autonomic nervous system. J Low Freq Noise Vib; Special Volume 1-12.

Grassi M, Rezzani C, Biino G, Marinoni A [2003]. Asthma-like symptoms assessment through ECHRS screening questionnaire scoring. J Clin Epidemiol 56(3):238-247, http://dx.doi.org/10.1016/S0895-4356(02)00613-3.

Griffin MJ, Howarth HVC, Pitts PM, Fischer S, Kaulbars U, Donati PM [2006]. Guide to good practice on hand-arm vibration. European Commission Directorate General Employment, Social Affairs and Equal Opportunities (contract VC/2004/0341).

Hagberg M, Kolmodin-Hedman B, Lindahl R, Nilsson CA, Norstrom A [1985]. Irritative complaints, carboxyhemoglobin increase and minor ventilator function changes due to exposure to chain saw exhaust. Eur J Respir Dis 66(4):240-247.

Harrison R, Materna BL, Rothman N [1995]. Respiratory health hazards and lung function in wildland fire fighters. Occup Med 10(4):857-870.

Health and Safety Executive [2018]. Initial screening questionnaire for workers using handheld vibrating tools, hand-guided vibrating machines and hand-fed vibrating machines, http://www.hse.gov.uk/vibration/hav/advicetoemployers/inscrquest.pdf.

Hewitt S, Dong RG, Welcome DE, McDowell TW [2015]. Commentary anti-vibration gloves? Ann Occup Hyg 59(2):127-141, http://dx.doi.org/10.1093/annhyg/meu089.

Hooper B, Parker R, Todoroki C [2017]. Exploring chainsaw operator occupational exposure to carbon monoxide in forestry. J Occ Env Hyg 14(1):D1-D12, https://doi.org/10.1080/15459624.2016.1229483.

International Agency for Research on Cancer [2012]. IARC monographs on the evaluation of carcinogenic risks to humans. Wood dust. Vol. 100C-15. Lyon, France: World Health Organization, International Agency for Research on Cancer, http://monographs.iarc.fr/ENG/Monographs/vol100C/mono100C-15.pdf.

ISO [2001a]. ISO 5349-1: mechanical vibration -- measurement and evaluation of human exposure to hand-transmitted vibration -- Part 1: general requirements. Geneva, Switzerland: International Organization for Standardization.

ISO [2001b]. ISO 5349-2: mechanical vibration -- measurement and evaluation of human exposure to hand-transmitted vibration -- Part 2: practical guidance for measurement at the workplace, Geneva, Switzerland: International Organization for Standardization.

Johnson A, Morata TC [2009] 142. Occupational exposure to chemicals and hearing impairment. The Nordic Expert Group for Criteria Documentation of Health Risks from Chemicals 44(4):1-190, https://gupea.ub.gu.se/bitstream/2077/23240/1/gupea_2077_23240_1.pdf.

Lipoglavsek M [2000]. Chain saw workers' loads of carbon monoxide. Gozdarski Vestnik 58(3):127-138.

Health Hazard Evaluation Report 2015-0028-3330 
Marchi E, Neri F, Cambi M, Laschi A, Foderi C, Sciarra G, Fabiano F [2017]. Analysis of dust exposure during chainsaw forest operations. iForest 10:341-347, http://iforest.sisef.org/contents/?id=ifor2123-009.

Masterson EA, Themann CL, Luckhaupt SE, Li J, Calvert GM [2016]. Hearing difficulty and tinnitus among U.S. workers and non-workers in 2007. Am J Ind Med 59(4):290-300, https://doi.org/10.1002/ajim.22565.

National Center for Health Statistics [2014]. National Health Interview Survey, hearing supplement (Adult).

ftp://ftp.cdc.gov/pub/Health_Statistics/NCHS/Survey_Questionnaires/NHIS/2014/English/ qadult.pdf.

National Park Service [2017]. Wildland fire: what is hazard fuel reduction?

https://www.nps.gov/articles/what-is-hazard-fuel-reduction.htm.

NIOSH [1972]. Criteria for a recommended standard: occupational exposure to carbon monoxide. Cincinnati, OH: U.S. Department of Health, Education, and Welfare, Health Services and Mental Health Administration, National Institute for Occupational Safety and Health, DHEW (NIOSH) Publication No. 73-11000.

NIOSH [1977]. Occupational diseases: a guide to their recognition. Rev. ed. Cincinnati, OH: U.S. Department of Health, Education, and Welfare, Center for Disease Control, National Institute for Occupational Safety and Health, DHEW (NIOSH) Publication No. 77-181.

NIOSH [1979]. A guide to work-relatedness of disease. Rev. ed. Cincinnati, OH: U.S. Department of Health, Education, and Welfare, Center for Disease Control, National Institute for Occupational Safety and Health, DHEW (NIOSH) Publication No. 79-116.

NIOSH [1989]. Criteria for a recommended standard: occupational exposure to hand-arm vibration, Cincinnati, OH: U.S. Department of Health and Human Services, Centers for Disease Control, National Institute for Occupational Safety and Health, DHHS (NIOSH) Publication No. 89-106.

NIOSH [1998]. Criteria for a recommended standard: occupational noise exposure (revised criteria 1998). Cincinnati, OH; U.S. Department of Health and Human Services, Centers for Disease Control and Prevention, National Institute for Occupational Safety and Health, DHHS (NIOSH) Publication No. 98-126.

NIOSH [2010]. NIOSH pocket guide to chemical hazards. Cincinnati, OH: U.S. Department of Health and Human Services, Centers for Disease Control and Prevention, National Institute for Occupational Safety and Health, DHHS (NIOSH) Publication No. 2010-168c, http://www.cdc.gov/niosh/npg/. 
NIOSH [2019]. NIOSH manual of analytical methods (NMAM). 5th ed. O'Connor PF, Ashley K, eds. Cincinnati, OH: U.S. Department of Health and Human Services, Centers for Disease Control and Prevention, National Institute for Occupational Safety and Health, DHHS (NIOSH) Publication No. 2014-151, http://www.cdc.gov/niosh/nmam.

Perez-Rios M, Ruano-Ravinia A, Etminian M, Takkouche B [2010]. A meta-analysis on wood dust exposure and the risk of asthma. Allergy 65(4):467-473, https://doi.org/10.1111/j.1398-9995.2009.02166.x.

Proctor NH, Hughes JP, Fischman ML [1988]. Carbon monoxide. In: Chemical hazards of the workplace. 2nd ed. New York, NY: Van Nostrand Reinhold, New York.

Proctor NH, Hughes JP, Fischman ML [1991]. Wood dust. In: Chemical hazards of the workplace. 3rd ed. Philadelphia, PA: J.B. Lippincott Company, Philadelphia.

Rosso M, Agius R, Calleja N [2011]. Development and validation of a screening questionnaire for noise-induced hearing loss. Occ Med 61(1):416-421, https://doi.org/10.1093/occmed/kqr059.

Schaette R, McAlpine D [2011]. Tinnitus with a normal audiogram: physiological evidence for hidden hearing loss and computational model. J Neurosci 31(38):13452-13457, https://doi.org/10.1523/JNEUROSCI.2156-11.2011.

Sutinen P, Toppila E, Stark J, Brammer A, Zou J, Pyykko I [2006]. Hand-arm vibration syndrome with use of anti-vibration chain saws; 19-year follow-up study of forestry workers. Int Arch Occup Environ Health 79(8):665-671, https://doi.org/10.1007/s00420-006-0099-2.

Tak S, Davis RR, Calvert GM [2009]. Exposure to hazardous workplace noise and use of hearing protection devices among US workers-NHANES, 1999-2004. Am J Ind Med 52(5):358-371, http://dx.doi.org/10.1002/ajim.20690.

Welcome DE, Dong RG, Xu XS, Warren C, McDowell TW [2016]. Tool-specific performance of vibration-reducing gloves for attenuating fingers-transmitted vibration. Occup Ergon 13(1):23-44, https://doi.org/10.3233/OER-160235.

Wimer BM, McDowell TW, Xu XS, Welcome DE, Warren C, Dong RG [2010]. Effects of gloves on the total grip strength applied to cylindrical handles. Int J Ind Ergon 40(5):574-583, https://doi.org/10.1016/j.ergon.2010.05.004. 
Keywords: North American Industry Classification System (NAICS) 115310 (Support Activities for Forestry), Utah, Wildland Fire Fighters, Fuel Reduction, Carbon Monoxide, Wood Dust, Noise, Hand-Arm Vibration, Chainsaw 
The Health Hazard Evaluation Program investigates possible health hazards in the workplace under the authority of the Occupational Safety and Health Act of 1970 (29 U.S.C. § 669(a) (6)). The Health Hazard Evaluation Program also provides, upon request, technical assistance to federal, state, and local agencies to investigate occupational health hazards and to prevent occupational disease or injury. Regulations guiding the Program can be found in Title 42, Code of Federal Regulations, Part 85; Requests for Health Hazard Evaluations (42 CFR Part 85).

\section{Disclaimer}

The recommendations in this report are made on the basis of the findings at the workplace evaluated and may not be applicable to other workplaces.

Mention of any company or product in this report does not constitute endorsement by NIOSH.

Citations to Web sites external to NIOSH do not constitute NIOSH endorsement of the sponsoring organizations or their programs or products. NIOSH is not responsible for the content of these Web sites. All Web addresses referenced in this document were accessible as of the publication date.

\section{Acknowledgments}

Analytical Support: Maxaam Analytics

Desktop Publisher: Shawna Watts

Industrial Hygiene Field Assistance: Eric Glassford

Logistics: Donnie Booher, Kevin Moore

Medical Field Assistance: Xiangning Fan, Isabel Liu

Statistical Support: Charles Mueller

\section{Availability of Report}

Copies of this report have been sent to the employer and employees at the facility. The state and local health department and the Occupational Safety and Health Administration Regional Office have also received a copy. This report is not copyrighted and may be freely reproduced.

\section{Recommended citation for this report:}

NIOSH [2019]. Evaluation of wildland fire fighter exposures during fuel reduction projects. By Ramsey JG, Eisenberg J, Wiegand D, Brueck SE, McDowell TW. Cincinnati, OH: U.S. Department of Health and Human Services, Centers for Disease Control and Prevention, National Institute for Occupational Safety and Health, Health Hazard Evaluation Report 2015-0028-3330, https://www.cdc.gov/niosh/hhe/reports/ pdfs/2015-0028-3330.pdf. 
Delivering on the Nation's promise:

Promoting productive workplaces through safety and health research

To receive NIOSH documents or more information about occupational safety and health topics, please contact NIOSH:

Telephone: 1-800-CDC-INFO (1-800-232-4636)

TTY: 1-888-232-6348

CDC INFO: www.cdc.gov/info

or visit the NIOSH Web site at www.cdc.gov/niosh

For a monthly update on news at $\mathrm{NIOSH}$, subscribe to

$\mathrm{NIOSH}$ eNews by visiting www.cdc.gov/niosh/eNews. 